\title{
empresa y familia en la agroindustria azucarera tucumana: el caso de la firma "avellaneda \& terán” (1907-1949)
}

\author{
Daniel Moyano ${ }^{\star}$ \\ Instituto Superior de Estudios Sociales (CONICET-UNT)
}

\section{RESUMO}

Propomo-nos a analisar aspectos específicos dos empresários do açúcar argentino, a partir do estudo da firma "Avellaneda \&Terán", empresa familiar, proprietária da usina "Los Ralos”, na província de Tucumán. Este caso é de interesse particular, pois a propriedade e o controle da empresa permaneceram dentro do núcleo familiar, alcançando um desempenho aceitável até o meado do século XX. Mesmo assim, este estabelecimento situa-se em um tipo geral de usinas de açucar de Tucumán, de modo que seu estudo abre a possibilidade de chegar a conclusões mais gerais. Por sua vez, esta abordagem permitirá um maior aprofundamento do estudo das empresas familiares como forma típica de propriedade e gestão empresarial em regiões de industrialização incipiente.

Palavras-chave:Família - Empresa - Açúcar - Tucumán - Indústria

\section{RESUMEN}

Nos proponemos analizar aspectos específicos del empresariado azucarero argentino a partir del estudio de la firma "Avellaneda \& Terán”, empresa familiar propietaria del ingenio 'Los Ralos', en la provincia de Tucumán. Este caso reviste especial interés por haber permanecido la propiedad y el control de la empresa dentro del núcleo familiar, logrando una aceptable performance hasta mediados del siglo $\mathrm{XX}$.Asimismo, el establecimiento azucarero puede ubicarse dentro del tipo general de ingenios componentes del parque azucarero tucumano, de manera tal que su estudio abre la posibilidad para arribar a conclusiones de alcance general. Este abordaje permitirá, a la vez, profundizar en el estudio de las 'empresas familiares' como forma típica de propiedad y gestión empresaria en regiones de industrialización incipiente.

Palabras clave: Familia - Empresa - Azúcar - Tucumán - Industria

* El autor agradece los comentarios y sugerencias realizados por los evaluadores anónimos de la Revista de História Económica \& História de Empresas. Además, deseo hacer extensivo el reconocimiento al Dr. Roque Avellaneda y Luisa Fagalde por permitirme la consulta del material de archivo de la empresa "Avellaneda \& Terán”, ingenio Los Ralos. Submetido em julho, 2010; aceito em junho, 2011. 


\section{Introducción}

La industria azucarera tucumana -cuya génesis puede ubicarse en los albores del siglo XIX- experimentó un profundo proceso de transformación y modernización en un corto período de tiempo, conocido en la historiografía como "despegue azucarero" (1876-1896), donde confluyeron diversos factores como la conexión ferroviaria de Tucumán con el litoral en 1876, la constitución del mercado nacional y el decidido apoyo brindado por el poder central al desarrollo agroindustrial azucarero, manifiesto en tarifas aduaneras específicas, exención impositiva a la importación de maquinaria, inversión directa en infraestructura, modernización del sistema financiero y la reducción de las tasas de interés. Estimulados por estas condiciones, diversos actores pertenecientes a la élite local decidieron invertir gran parte de sus capitales (otrora acumulados en el comercio interregional y en algunas actividades productivas) en este nuevo modelo de desarrollo basado en la industrialización moderna del azúcar. Esta actividad representó uno de los ensayos industriales más tempranos del interior del país y, junto a la moderna vitivinicultura en Mendoza y San Juan, generaron alternativas regionales de desarrollo, vinculándose de modo indirecto con el proceso de expansión de la Argentina agroexportadora (CAMPI Y BRAVO, 1999: 76; CAMPI a, 2000) ${ }^{1}$.

Pese a ser Tucumán un área azucarera reducida, albergó entre 35 y 27 ingenios en el período comprendido entre 1895 y 1940, conformándo-

se un espectro empresarial sumamente diverso, que operó en una amplia gama de empresas con diferentes tipos societarios y escalas productivas. Sin embargo, a pesar de su heterogeneidad, una parte importante de los ingenios en la provincia pertenecieron, por lo menos hasta la década de 1940, a empresas tucumanas de propiedad y control familiar.

1 Para una visión amplia sobre el desenvolvimiento de la industria azucarera en Tucumán, pueden consultarse los trabajos de (GUY, 1981) y (SÁNCHEZ ROMÁN, 2005a). 
Nuestro caso bajo análisis corresponde justamente a este rango de firmas surgida al calor de las condiciones que ofrecía la actividad azucarera a finales del siglo XIX, y que, más allá de ciertos altibajos, evidenció una aceptable performance hasta la década de 1940. Nos referimos a la firma “Avellaneda \& Terán”(A\&T), propietaria del ingenio azucarero "Los Ralos", ubicado en el departamento Cruz Alta, principal distrito cañero de la provincia. Se trató de una mediana empresa familiar que a pesar de modificar en dos oportunidades su razón social, pasando a 'comandita por acciones' en 1908 y finalmente a "Sociedad Anónima" en 1949, tanto la propiedad como el control de la empresa permanecieron dentro del núcleo familiar primigenio.

Nuestra propuesta se enmarca dentro de la corriente de estudios que enfatiza las posibilidades de análisis sobre aspectos que van más allá del desenvolvimiento netamente económico, en tanto se concibe a las empresas más como un 'sujeto' que como una función de la producción (SAPELLI, 1993:105). De modo tal que, a través de un enfoque microanalítico, se busca combinar el análisis de su desempeño económico con sus estrategias de reproducción patrimonial, el rol jugado por la familia en la empresa, sus redes sociales y las características de la gestión, aspectos de suma importancia a la hora de evaluar el desenvolvimiento de esta agroindustria en general y el comportamiento empresarial en particular.

Existen diferentes maneras de abordar el estudio de las empresas ${ }^{2}$. Sin embargo, nos interesan especialmente los aportes que toman a la firma como un centro de recursos, capacidades y conocimientos, que aprende y evoluciona con la experiencia. Esta postura, con una influencia notoria de la economía evolutiva, destaca la flexibilidad y capacidad de adaptación de la firma, lo que permite combinar el estudio de las trayectorias y estrategias de desarrollo, junto a la historia de las personas que comandaron la marcha de los negocios (PENROSE, 1959; NELSON-WINTER, 2005; BARBERO-ROCCHI, 2006; LÓPEZ, 2006). De este modo, la firma se la puede concebir como un ámbito de interacción social en la que se construyen, saberes, creencias, tradiciones y

2 Para un balance sobre los diferentes paradigmas de la historia de empresas, puede consultarse un completo estudio en (BARBERO- ROCCHI, 2004). También (VALDALISO y LÓPEZ GARCÍA, 2000) y (FERNÁNDEZ PÉREZ, 2003). 
pericias específicos, siendo en las empresas familiares de larga trayectoria donde se desarrollan visiblemente estos elementos.

En estrecha conexión, hemos optado por seguir la propuesta de Sapelli, quien define a la firma como una asociación de personas, de sus voluntades y de sus capacidades cognoscitivas y como la cristalización de una construcción social. La considera como un lugar en el que se encuentran las racionalidades económicas con las normas, el conocimiento acumulado y la cultura a través de un proceso histórico en el que se dan el conflicto y la cooperación y que tiene como protagonistas a todas las personas de la empresa, con roles y distribución del poder (SAPELLI, 1996:76).

Por lo tanto, nuestro trabajo puede encuadrarse dentro de la vertiente historiográfica cuyo objeto es la historia de la empresa y los empresarios en una perspectiva histórica, destacando el rol de los actores y sus estrategias en contextos que pueden ofrecer oportunidades de desarrollo como también limitaciones, y que son, a la vez, construidos por los mismos agentes (BARBERO, 2006:154).

Desde el punto de vista metodológico, es imprescindible dejar sentado que el derrotero seguido por una empresa involucra una serie de sucesos particulares y específicos, que dificultan todo intento de generalización. Sin desconocer lo aleatorio que pueda tener su trayectoria, colocado el estudio de caso apropiadamente en su contexto, ayuda a explicar procesos que incidieron en el conjunto de la actividad. En este sentido, el estudio de "Avellaneda \& Terán" ofrece elementos valiosos para entender cómo las firmas azucareras se vieron afectadas y a su vez reaccionaron en un contexto inestable como fue la actividad azucarera argentina durante la primera mitad del siglo XX.

Sobre este último punto, aun no se ha arribado a una definición clara e inequívoca de "empresa familiar". Aquí tomaremos la tesis que la considera como aquel emprendimiento comercial o productivo en el que la mayoría accionaria y el control recaen en una familia y en el que dos o más miembros mantienen la dirección de la firma (ROSEMBLATT et al, 1990). Asimismo, nos apoyaremos en la propuesta sistémica, que la entiende como una estructura conformada por la superposición de tres sistemas: el sistema familiar, el sistema de propiedad y el sistema organizacional (GERSICK et al, 1997). De este modo, una sociedad colectiva o una Sociedad Anónima pueden considerase fami- 
liares, en tanto cumplan con los requisitos expuestos. A través de estas premisas, intentaremos aproximarnos al dilema sobre la incidencia "negativa" de la familia en el manejo de las empresas, por su supuesta tendencia indefectible al conservadurismo y la ineficiencia ${ }^{3}$.

Por tal motivo, la elección del tema no es azarosa, sino que responde principalmente a la necesidad de problematizar el análisis sobre esta agroindustria. Creemos que a través del análisis de esta firma se logrará una comprensión un poco más acabada sobre el desenvolvimiento azucarero tucumano, al permitir analizar y comparar empresas "tipo" dentro de la lógica de este parque azucarero, permitiendo discutir las posturas que consideran a las grandes empresas como modelo unívoco de éxito empresarial, y dar cuenta de las diferentes trayectorias que desarrollaron firmas de escalas productivas 'medianas', de propiedad y control familiar.

\section{Una necesaria contextualización}

Los orígenes de la producción azucarera argentina pueden ubicárselos a inicios del siglo XIX, en establecimientos rudimentarios y con métodos preindustriales, orientada su elaboración para abastecer principalmente al mercado regional. Sin embargo, durante la segunda mitad de la centuria y, sobre todo en el último tercio, se desarrolló una moderna agroindustria equipada con la tecnología más avanzada del mo-

3 Chandler sostiene que hacia fines del siglo XIX, la empresa "patronal" fue progresivamente reemplazada por la "empresa gerencial", donde la dirección estuvo desempeñada por ejecutivos profesionales y asalariados. Así se dio paso a la "empresa gerencial moderna", con estructura multidivisional y mayor racionalidad en la dirección. Este fenómeno - según el autor - habría tenido lugar antes y en mayor medida en Estados Unidos y luego en Alemania, mientras que en Gran Bretaña habría predominado una empresa y un capitalismo patronal o personal, lo que explicaría su menor competitividad y el retraso económico respecto a sus nuevos competidores (CHANDLER, 1987,1990). Algunos visiones críticas sobre la "estrechez" del paradigma chandleriano dentro de la comunidad académica pueden consultarse en las obras de Scranton (para Estados Unidos) y Lislie Hanna (para Inglaterra), entre otros. Para un completo balance sobre estos debates y las nuevas propuestas desarrolladas, sobre todo, desde los estudiosos europeos agrupados en el denominado "paradigma alternativo " véase (BARBERO-ROCCHI, 2006: 108, 111-113; FERNÁNDEZ PÉREZ, 2003: 45-66). 
mento, representando, de este modo, una de las primeras manifestaciones de la segunda fase de la revolución industrial en Argentina. Uno de los aspectos característicos de este complejo azucarero fue que la zona climática apta para el cultivo cañero se encontraba en el extremo Norte del país, a más de $1.000 \mathrm{Km}$ de los mayores puertos comerciales y del principal mercado consumidor, ubicado en las grandes urbes de la región pampeana. Por otra parte, y a diferencia de los centros cañicultores latinoamericanos, su producción se destinó enteramente a abastecer el mercado interno. Esto hizo que el caso argentino sea más afín al de Morelos en México o Luisiana en los Estados Unidos, que a los complejos azucareros de Cuba, Puerto Rico o Perú, orientados fuertemente a la exportación (SÁNCHEZ ROMÁN b, 2005: 147-172).

Otra característica de la producción argentina fue la elaboración de azúcares para el consumo directo en sus propios establecimientos, apartándose de la división del trabajo establecida entre ingenios productores de azúcar crudo y refinerías que elaboraban el producto final. Si bien a finales de la década de 1880 comenzó a funcionar la "Refinería Argentina" en la ciudad de Rosario, la producción nacional se compuso en todo momento de azúcares 'blancos' fabricados en los ingenios, una proporción de azúcares "rudo" y "bajos productos" para refinar, y los "refinados" de calidad superior. Esta particularidad diferenció al complejo argentino de otros centros productores latinoamericanos que como Cuba, Perú o Brasil, fabricaban azúcares crudos o mascavados para enviar la totalidad de la producción a refinar en el exterior o en las refinerías locales (MORENOS FRAGINALS, 1986; CAMPI-JUAREZ DAPPE, 2006; SUZIGAN, 2000).

La actividad azucarera argentina, como vimos, se modernizó y transformó radicalmente sobre la base de ciertas medidas de estímulo por parte del Estado nacional. Su área de desarrollo se ubicó en el Norte del país, principalmente en la provincia de Tucumán y, en menor medida, en las también norteñas provincias de Salta y Jujuy. Posteriormente se erigieron algunos ingenios en la región mesopotámica (sobre todo en la provincia de Santa Fe y en el entonces Territorio Nacional del Chaco), aunque su participación en la producción nacional representó cifras menores.

Empero, si Tucumán rápidamente tomó la delantera en la producción del dulce, en comparación con las otras provincias, fue gracias a la con- 
formación de una burguesía local con una larga tradición en el sector mercantil y productivo (como rubros más destacados) y la agricultura y elaboración del dulce con métodos preindustriales (como actividades complementarias). Estos actores económicos estuvieron en condiciones de aprovecharse de la nueva situación creada por el auge agroexportador, construyendo políticamente alianzas con los intereses del litoral para generar un acople en la expansión económica de la región pampeana. Esta vía de desarrollo fue la especialización en un producto de consumo masivo como el azúcar para ser colocado en el mercado del litoral en expansión. De este modo, la élite local invirtió gran parte de los capitales acumulados previamente en el comercio y las manufacturas en la moderna actividad azucarera, promoviendo su desarrollo y expansión (CAMPI a, 2000; SÁNCHEZ ROMÁN a, 2005).

La característica de la producción azucarera argentina, orientada decididamente al mercado interno, otorgó una especial importancia al equilibrio entre la oferta y la demanda interna, para generar un desenvolvimiento en la actividad sin mayores sobresaltos. Hasta la década de 1890 los ingenios norteños todavía no estaban en condiciones de abastecer el consumo nacional. Por lo tanto, el faltante de azúcar se compensaba con la importación de similares extranjeros de mejor calidad. Sin embargo, las buenas perspectivas de la actividad hicieron crecer el monto de las inversiones y la expansión del cultivo de la caña en toda la provincia, el cual pasó de 2.200 has en 1876, con una producción de 3.000 tn de azúcar, a 40.724 has y 114.291 tn, en 1895. De este modo, y una vez que la zafra de 1895 arrojó una producción que sobrepasó la capacidad de consumo del mercado interno, se dio inicio a la primera crisis de sobreproducción en 1895-96 (CAMPI, 2002). Estas crisis cíclicas de sobreoferta de azúcar representaron una característica de la actividad en Argentina, producto de la inelasticidad de la demanda y de la fuerte dependencia de un solo mercado, puesto que resultaba imposible exportar los excedentes a precios remunerativos, por sus costos productivos elevados en comparación con los grandes productores mundiales.

Luego de varios intentos por descomprimir el mercado sobre la base de acuerdos entre los productores para exportar parte de los excedentes y ordenar la venta de los stocks acumulados; y luego de más de un quinquenio de sobreoferta y estancamiento de precios, se decidió buscar una solución no ya en la fase de la comercialización sino en la esfera de la producción 
(LENIS, 2009). En efecto, en 1902 y 1903, a instancias de un sector de industriales y plantadores independientes, el gobierno provincial dictó leyes limitadoras de la producción (conocidas como "Leyes Machete") consistentes en la erradicación de cañaverales y la distribución de cupos de producción entre los ingenios. Estas leyes fueron declaradas inconstitucionales tras la demanda de varias empresas, pero significaron el primer intento por regular la actividad y otorgarle mayor solidez ante los recurrentes desequilibrios provocados por la sobreproducción (BRAVO, 1993).

Sin embargo, hacia 1906 el ciclo expansivo cambió de signo. A partir de entonces, se experimentaron dificultades para cumplir satisfactoriamente con las necesidades del mercado, debido a los bajos rindes de los cañaverales tucumanos. En este contexto, cobró importancia para los actores involucrados en la actividad la experimentación con nuevas variedades de cañas. Asimismo, acompañando este proceso, se promovió entre un sector de industriales la creación de una institución científica para la modernización agrícola de la industria, como fue la Estación Experimental Agrícola de Tucumán ${ }^{4}$.

Esta introducción, aunque necesariamente incompleta, nos brinda a grandes rasgos el contexto de desarrollo de la agroindustria azucarera tucumana, y nos permite pasar al análisis del desenvolvimiento de "Avellaneda y Terán”, y por su intermedio, interiorizarnos sobre algunos rasgos de las empresas componentes del sector.

\section{La gestión de la empresa}

\section{La opción por la continuidad}

Analizando a simple vista la secuencia de los administradores de la firma en el período abordado, la sociedad tuvo como cabezas visibles a dos miembros de las familias fundadoras: Brígido Terán, entre 1891 y 1922, y Eudoro Avellaneda (h), desde ese año hasta 1949, en que la empresa se conformó en Sociedad Anónima. Sin embargo, un análisis

4 Para un análisis integral sobre la creación y funcionamiento de la Estación Experimental de Tucumán, en entre 1909 y 1922, me permito sugerir al lector el trabajo de (MOYANO-LENIS-CAMPI, 2007). 
detenido sobre la conformación del Directorio, la incorporación de parientes políticos a la sociedad y la distribución de las acciones entre sus miembros puede arrojar luz sobre la función cohesionadora que desempeñaron las redes sociales dentro de la empresa. Por otra parte, se puede indagar sobre la actitud de los directivos de la firma ante uno de los escollos más importantes en la vida de las empresas familiares: el traspaso del mando a la generación siguiente. Desde esta perspectiva, pretendemos aproximarnos a una imagen más acabada sobre la dinámica interna de las empresas azucareras tucumanas durante esta etapa, y sobre las características de los empresarios del sector.

La firma "Avellaneda \& Terán" formalizó su constitución como 'sociedad colectiva' en agosto de 1879, aunque ya giraba de "hecho" en la plaza tucumana desde 1877. Estuvo formada desde sus inicios por Marco y Eudoro Avellaneda (ambos hermanos del entonces Presidente de la Nación Nicolás Avellaneda, durante1874-1880), y por su primohermano Brígido Terán Silva, que era a la vez cuñado de Eudoro por su matrimonio con Rosa Delfina Terán Silva, hermana de Brígido. El objetivo que motivó esta asociación fue ingresar al entonces promisorio negocio del azúcar mediante la instalación de un ingenio al naciente de la capital tucumana.

A pesar de la buena marcha de los negocios, una década después de fundada la empresa, el socio Marco se radicó en la ciudad de Buenos Aires, dedicándose de lleno a la actividad política. Los socios restantes decidieron mantenerse en el rubro azucarero acordando en 1888 la compra de los derechos y su definitiva desvinculación. A partir de entonces, la firma continuó sus actividades administrada por Brígido en todo lo relacionado con la fábrica y plantaciones, y por Eudoro en lo que respecta a la administración general en el escritorio ubicado en la capital tucumana ${ }^{5}$.

Sin embargo, esta división de tareas no duró mucho tiempo, pues en 1891 el socio Eudoro falleció de manera inesperada. Un año después, por pedido expreso de Brígido, los cuatro hijos y herederos Avellaneda entraron a formar parte de la empresa, incorporando su capital hereditario. De acuerdo al contrato de continuación de la sociedad, formalizado en septiembre de 1892, la participación de los herederos Sofía,

5 Archivo Histórico de Tucumán (AHT). Sección Protocolo. Serie A. f. 248. 
Eudoro (h), Delfina y María (todos menores de edad, a cargo de Hipólita Silva de Terán, madre de Brígido y suegra del difunto Eudoro) representaban un poco más de la mitad del total de las propiedades, entre terrenos e ingenio ${ }^{6}$. Sobre este punto es conveniente detenernos un momento, pues resulta interesante indagar sobre las razones por las que se decidió la incorporación de los herederos menores a la firma.

En el contrato de continuación de la sociedad, Brígido Terán argumentó el desatino que significaría liquidar la firma en una etapa sumamente favorable para el negocio azucarero, que permitía la obtención de altas utilidades y redundaba en beneficio de los herederos. En este sentido afirmaba:

No entraré a enumerar las razones que hacen ventajosa esta sociedad para los menores porque no es misterio para nadie las condiciones excepcionales en que se encuentra la industria azucarera en nuestra provincia. Me bastará recordar a S.S. que el año pasado ha producido solo el ingenio una utilidad líquida para los herederos del Sr. Avellaneda de ciento treinta y cinco mil pesos y este año será aún mayor quizás ${ }^{7}$.

Por su parte, Hipólita Silva de Terán (en representación de sus nietos menores), confirmaba la buena marcha del negocio azucarero, además de presentar otras razones complementarias de gran interés. Afirmaba la tutora que la liquidación de la firma implicaría pérdidas para los herederos Avellaneda, puesto que el remate público provocaría la venta de los bienes a un precio muy inferior, sin relación con su potencialidad. Pero además sostuvo que "[...] si a esto se agrega que el proponente ha sido y es hasta ahora socio en el ingenio expresado, se llegará fácilmente a la siguiente conclusión: el ingenio de 'los Ralos', en venta pública, no tendrá más interesados que el mismo socio" ". Si bien es muy probable que en la circunstancia de un remate público hubieran existido más de un interesado, Brí-

6 La distribución era la siguiente: "cuatro y media octavas partes en el ingenio 'Los Ralos' con sus maquinarias, plantíos y accesorios y terrenos de 'Pereiras", o sea el 56,25\%; y la de Brígido Terán "tres y media octavas partes", es decir el 43,75\%. En el resto de los bienes sociales la participación de los herederos de E. Avellaneda y de B.Terán era de un 50\% por cada parte.AHT, Sección Judicial Civil, Serie A, 1892, Expte. 15, Caja 241 ff. 1-12.

7 A.H.T. Sección Judicial Civil. Serie A. Año 1892. Expte 15. Caja 241. f. 3 v. 8 Ídem. 
gido Terán, amparado por la legislación comercial, habría tenido preferencia en la venta, la cual se habría realizado a un precio muy conveniente para este último.

En definitiva, no habría existido obstáculo alguno para que el ingenio quedara en manos del socio sobreviviente de no haber mediado la decisión de incorporar a los herederos en la firma. Es probable que el lazo afectivo tuviera un peso importante en esta decisión, pero también puede vislumbrarse el interés por preservar no sólo la empresa en la familia, sino también introducir la familia en la empresa. Esta tendencia, como veremos, se reafirmó en años posteriores con la incorporación de parientes en cargos directivos de la firma, incluyendo también a familiares políticos ${ }^{9}$.

En 1907, Brígido Terán impulsó la reconversión de la firma, pasando de "Sociedad Colectiva" a "Sociedad en comandita por acciones". Su capital social se fijó en $\$ 2.550 .000 \mathrm{~m} / \mathrm{n}$ dividido en 2.500 acciones de $\$ 1.000 \mathrm{~m} / \mathrm{n}$ cada una. En la repartición del capital correspondió 995 acciones (39\%) para Brígido Terán, seguido por Eudoro Avellaneda (h) con 360 acciones (14\%). El resto se repartió entre las herederas de Eudoro padre, con el 10\% para cada una de sus tres hijas. Además se decidió la incorporación a la firma de familiares políticos de la línea Avellaneda (Evaristo Etchecopar, Julio J. Cainzo y Ezequiel Gallo, todos casados con las socias Avellaneda) ${ }^{10}$; un hijo de Brígido, Juan Manuel Terán Vega, y su cuñado Lauro N. Fagalde, a quien su suegro Brígido le cedió 46 acciones para su incorporación. ${ }^{11}$ Estos datos no dejan de llamar la atención en

9 Es importante remarcar el complejo juego de alianzas familiares gestada a través de los vínculos de matrimonios pues, como veremos, los socios de la firma se casaron con miembros de importantes familias de la elite comercial y azucarera de Tucumán. No nos detendremos a analizar las implicancias políticas de este tipo de alianzas por razones de espacio y porque creemos que fueron suficientemente analizadas en otros trabajos. En este sentido, puede consultarse (CAMPI, 2006) y (HERRERA, 2006). No caben dudas que estos lazos parentales permitieron contar con un capital relacional que permitió el acceso a información e influencias, contribuyendo a mejorar la situación de los negocios.

10 Sofía, María y Delfina Avellaneda se casaron, respectivamente, con Evaristo Etchecopar, Ezequiel Gallo y Julio J. Cainzo, miembros de importantes familias de la élite tucumana, además de pertenecer los dos primeros a reconocidas familias azucareras.

11 Archivo del Poder Judicial de Tucumán (APJT), Registro Público de Comercio (RPC), Contratos Mercantiles (CM), Tomo VI, 4/06/1907. fs. 390-406. 
tanto nuevamente observamos cómo se estimuló la incorporación de parientes dentro de la empresa, incluso a través de la cesión de acciones, viniendo a confirmar la tendencia iniciada en 1892 de abrir el ingreso de los parientes a la firma, conformando un sólido entramado de vínculos entre la familia y la empresa. Sin embargo, a pesar de la incorporación de nuevos socios, debemos hacer notar que el 83\% del capital social siguió en manos de lo que podríamos denominar el "núcleo fundador", siendo Brígido su conductor indiscutido hasta antes de su muerte, ocurrida en 1922.

Otro elemento destacable fue la ausencia de los hijos mayores de Brígido en la sociedad, a pesar que se dedicaran a otro tipo de actividades, como la ganadería, el comercio y la compra-venta de inmuebles. A primera vista pareciera estar indicando una cierta independencia de los sujetos ante el "mandato familiar" (si es que lo hubo), o bien algún tipo de desavenencias entre padres e hijos, las cuales nos es imposible probar. De todas maneras, creemos que este caso (como otros tantos de este tipo) nos llama a prevenirnos de realizar asociaciones mecánicas y de otorgar cierta distribución de roles a los miembros de una familia, perdiendo de vista los márgenes de independencia de los actores, es decir, la relación entre decisiones individuales y estrategias colectivas (BJERG \& BOIXADÓS, 2004: 115-129).

Retomando las modificaciones de 1907, se conformó además el Directorio de la empresa con Brígido Terán como Presidente y Eudoro Avellaneda (h), sus cuñados y los parientes de la línea Terán como Vocales y únicos socios solidarios. De este modo, quedaron apartadas de la dirección de la empresa las socias Avellaneda, participando solamente en calidad de socias comanditarias. Esta decisión podría explicarse, en parte, por el modelo tradicional de empresa familiar, notoriamente patriarcal, que excluía a las mujeres de los ámbitos de decisión, aunque poseyeran una porción importante de la propiedad.

Pero la expansión de las actividades e inserción en el negocio del azúcar por parte de esta familia no se detuvo aquí. En este mismo año, por iniciativa de Brígido Terán, los socios solidarios de A\&T,junto al aporte de nuevos inversores, compraron el ingenio Santa Lucía y seis fincas cañeras. Dicha operación la emprendió Brígido junto a Evaristo Etchecopar, Eudoro Avellaneda (todos de A\&T), sus hermanos Juan Manuel (ingenio Santa Bárbara) y Belisario (abogado y Martillero), los hermanos José Frías Silva y Ricardo 
M. Frías (miembros de la familia azucarera propietaria del ingenio San José, y a la vez primos de la rama Avellaneda), Pedro Chenaut y Lucas M. Zavaleta (parientes de los Frías, y el primero socio solidario del ingenio San José), además de Jerónimo Helguera y Federico Erdmann, figuras destacadas del espectro político tucumano ${ }^{12}$.

Este establecimiento presentaba ciertas características que los hacían atrayente. Por un lado, estaba ubicado en la zona pedemontana del departamento de Monteros, área cañera con buenas perspectivas para una futura expansión, a diferencia del tradicional departamento azucarero de Cruz Alta. Además, la alternativa de adquirir una fábrica en funcionamiento era, en esa coyuntura, mucho más ventajosa que expandir la producción de Los Ralos o montar otro ingenio nuevo (CAMPI, 2006:226). Pero además, debemos agregar que este establecimiento no estaba gravado con deuda alguna, lo que representaba una clara ventaja, si lo comparamos con otros ingenios rematados o liquidados, cuyos nuevos propietarios debieron afrontar fuertes cargas en sus pasivos.

El ingenio Santa Lucía había sido fundado por Gerardo Constanti en 1882, pasando por diferentes sociedades, hasta quedar en propiedad exclusiva del socio Federico Moreno, en $1887^{13}$.Éste, al no dejar descendencia, determinó en su testamento la venta del ingenio y el destino de lo recaudado a diversas obras de beneficencia. Una vez fallecido Moreno en 1905, se iniciaron las disposiciones testamentarias y en 1907 se concretó la compra del establecimiento en $\$ 415.216,23 \mathrm{~m} / \mathrm{n}$, una operación muy favorable para entonces.

Este caso reviste un interés particular pues, como veremos, si por entonces entre las familias azucareras tucumanas se abrió la tendencia a conformar Sociedades Anónimas, Santa Lucía representó el único caso de asociacionismo empresarial azucarero para la compra y explotación de un ingenio ${ }^{14}$. Cabe preguntarse entonces cuáles fueron los

12 APJT, RPC, CM, Tomo VI, 22/4/1907. fs. 415-428. El capital social fue conformado por $\$ 401.000 \mathrm{~m} / \mathrm{n}$ dividido en 410 acciones de $\$ 1.000 \mathrm{c} / \mathrm{u}$, correspondiendo el valor del ingenio $\$ 267.827,29 \mathrm{~m} / \mathrm{n}$ y los restantes $\$ 142.172,71 \mathrm{~m} / \mathrm{n}$ aportados en efectivo.

13 Archivo Cámara de Justicia de la Provincia de Mendoza, 20/12/1887, Fs.130. Dato extraído de (MERCADO, 2003:140).

14 En diversas oportunidades se dio la asociación de empresarios azucareros para explotar un establecimiento. Sin embargo, se trató en realidad de arriendos de fábricas por cortos períodos de tiempo (de una a cinco zafras máximo), disolviéndose las 
motivos por los que se decidió conformar una S.A., en vez de otra razón social.

Lógicamente, los socios fundadores tenían una relación previa en diversos ámbitos como el familiar, el político o el comercial, que les otorgaban fuertes vínculos de confianza y reciprocidad. Por otra parte, tanto Erdmann como Chenaut figuraban como acreedores del ingenio Los Ralos en años previos (aunque en montos operativos menores), mostrando una extendida relación comercial con A\&T. ${ }^{15}$ Asimismo, los socios que se ubicaban fuera del vínculo familiar, estaban a la vez conectados por filiación política, nucleados algunos en el partido provincial "Unión Popular".

Por lo tanto, una explicación sobre la elección del formato de S.A. podría radicar en la apropiación y uso de esta forma jurídica con motivos netamente utilitarios. En efecto, de los 12 miembros fundadores, ocho participaban en otro emprendimiento azucarero y en todos ellos tenían responsabilidad solidaria en sus empresas por su calidad de socios comanditados (en “A\&T” y “Justiniano Frías y Cía."), o por ser único propietario, en el caso del ingenio Santa Bárbara.

Cuadro № 1 - Participación de los accionistas en diferentes empresas azucareras

\begin{tabular}{l|c|c|c|c|l|l}
\hline \multirow{2}{*}{ Accionistas } & \multicolumn{2}{|c|}{$\begin{array}{c}\text { Cía. Azuc. Santa } \\
\text { Lucía }(410 \\
\text { acciones/\$410.000) }\end{array}$} & \multicolumn{2}{|c|}{$\begin{array}{c}\text { Avellaneda \& Terán } \\
(2.550 \\
\text { acciones } \$ 2.550 .000)\end{array}$} & Ingenio & \multirow{2}{*}{$\begin{array}{c}\text { Tipo de } \\
\text { Responsabilidad }\end{array}$} \\
\cline { 2 - 6 } & acciones & $\%$ & acciones & $\%$ & & \\
\hline $\begin{array}{l}\text { Brígido } \\
\text { Terán }\end{array}$ & 100 & 24 & 995 & 39 & $\begin{array}{l}\text { Los } \\
\text { Ralos }\end{array}$ & Solidaria \\
\hline $\begin{array}{l}\text { Evaristo } \\
\text { Etchecopar }\end{array}$ & 50 & 12 & 100 & 4 & $\begin{array}{l}\text { Los } \\
\text { Ralos }\end{array}$ & Solidaria \\
\hline $\begin{array}{l}\text { Juan Manuel } \\
\text { Terán }\end{array}$ & 50 & 12 & & & $\begin{array}{l}\text { Santa } \\
\text { Bárbara }\end{array}$ & Solidaria \\
\hline $\begin{array}{l}\text { Lucas M. } \\
\text { Zavaleta }\end{array}$ & 50 & 12 & & & & \\
\hline
\end{tabular}

sociedades una vez concluido con su objetivo. Como ejemplos podemos mencionar la constitución de las firmas colectivas "Padilla y Berho", fundada en 1898 para explotar el ingenio La Invernada por dos cosechas; "Guillermo Hill y Cía.", para poner en funcionamiento el ingenio Amalia en la zafra de 1903; o "Hill y Terán", contrato firmado para explotar el ingenio El Manantial por el espacio de cinco cosechas. Véase APJT, RPC, CM, Tomo IV, 23/1/1898. fs. 146-149; Tomo V, 12/5/1903. fs. 469-470; Tomo IX, 25/9/1911. fs. 315-316.

15 Archivo A\&T, Libro "Inventario y Balance", 1892-1907. 
Cuadro № 1 - Participación de los accionistas en diferentes empresas azucareras

\begin{tabular}{|c|c|c|c|c|c|c|}
\hline $\begin{array}{l}\text { Guillermo F. } \\
\text { Erdmann }\end{array}$ & 50 & 12 & & & & \\
\hline $\begin{array}{l}\text { Ricardo M. } \\
\text { Frías }\end{array}$ & 25 & 6 & & & $\begin{array}{l}\text { San } \\
\text { José }\end{array}$ & Solidaria \\
\hline $\begin{array}{l}\text { José Frías } \\
\text { Silva }\end{array}$ & 25 & 6 & & & $\begin{array}{l}\text { San } \\
\text { José }\end{array}$ & Solidaria \\
\hline $\begin{array}{l}\text { Eudoro } \\
\text { Avellaneda }\end{array}$ & 15 & 4 & 360 & 14 & $\begin{array}{l}\text { Los } \\
\text { Ralos }\end{array}$ & Solidaria \\
\hline $\begin{array}{l}\text { Julio J. } \\
\text { Cainzo }\end{array}$ & 15 & 4 & 100 & 4 & $\begin{array}{l}\text { Los } \\
\text { Ralos }\end{array}$ & Solidaria \\
\hline $\begin{array}{l}\text { Pedro } \\
\text { Chenaut }\end{array}$ & 10 & 2 & & & $\begin{array}{l}\text { San } \\
\text { José }\end{array}$ & Solidaria \\
\hline $\begin{array}{l}\text { Jerónimo } \\
\text { Helguera }\end{array}$ & 10 & 2 & & & & \\
\hline $\begin{array}{l}\text { Belisario } \\
\text { Terán }\end{array}$ & 10 & 2 & & & & \\
\hline Totales & 410 & 100 & 1.555 & 61 & & \\
\hline
\end{tabular}

Fuente: Elaboración propia a partir de APJT, RPC, CM, Tomo VI, "Cía. Azucarera Santa Lucía”, 22/4/1907. fs 415-428; “Avellaneda \& Terán", 4/4/1907. fs. 390-406; Tomo V "Justiniano Frías y Cía.”, 30/9/1903. fs. 510-511.

De esta manera, el haber conformado una sociedad por acciones con responsabilidad limitada sólo al capital aportado les permitía a los socios cierta soltura en la administración de este nuevo emprendimiento, evitando que un mal resultado en Santa Lucía ponga en compromiso su patrimonio personal, y que repercutiera en el estado financiero de los ingenios de sus respectivas familias. Además, el número reducido de los socios y la cláusula estatutaria que la mayoría de las acciones fueran nominales, impedían su dispersión y el ingreso de nuevos socios ${ }^{16}$. De esta manera, a pesar de la estructura de una sociedad por acciones (con Directorio, Consejo consultivo y Asambleas de accionistas), en la práctica la firma pudo manejarse como una sociedad con una fuerte impronta personalista.

Como se desprende del cuadro siguiente, las acciones correspondieron del siguiente modo: 100 a Brígido Terán; Lucas Zavaleta, Guillermo

16 APJT, RPC, CM, Tomo VI, “Cía. Azucarera Santa Lucía”, 22/4/1907. fs 415-428. Se determinó que de las 410 acciones, 310 fueran nominales y no endosables, mientras las restantes 100 fueran al portador. De todas maneras, se repartieron en prorrata entre Brígido Terán y Juan M.Terán, Evaristo Etchecopar, Guillermo Erdmann y Lucas M. Zavaleta, con lo que sólo 40 acciones quedaron fuera del núcleo familiar. 
Erdmann, Evaristo Etchecopar y Juan M.Terán 50 acciones cada uno; los hermanos Frías Silva 25 acciones cada uno; Eudoro Avellaneda y Julio J. Cainzo 15 acciones cada uno; y Jerónimo Helguera, Pedro Chenaut y Belisario Terán 10 cada uno.Pero si prestamos atención a la distribución final de las acciones (que reflejan la participación en el capital social y el control de la firma), vemos que los socios de A\&T (ingenio Los Ralos) controlaban el 44\% del paquete accionario; el 14\% entre los hermanos Frías Silva y Chenaut (ingenio San José); el 12\% Juan M.Terán (ingenio Santa Bárbara); y el resto distribuido entre los demás socios.

El primer Directorio quedó conformado con Brígido a la cabeza como Presidente y Evaristo Etchecopar como Vicepresidente. Los cargos de vocal se distribuyeron entre L. Zavaleta, F. Erdmann, J. Frías Silva, R. M. Frías y J. Cainzo; y los síndicos fueron Juan M. Terán y Eudoro Avellaneda (h).

De esta manera, la gestión de la empresa quedó controlada desde el principio por los socios de A\&T. La elección de Brígido como cabeza de la firma, además de poseer la mayor porción del paquete accionario, obedeció, sin duda, a su amplia trayectoria y conocimiento cabal del negocio azucarero, reforzando el rol de A\&T como empresa líder dentro del grupo. A esta experiencia empresarial se le sumaron las habilidades y el capital relacional de los socios Frías, Avellaneda,Terán y demás accionistas, todos elementos que conformaron una base amplia de activos intangibles trasladados por las familias desde sus respectivas empresas que facilitaron a la nueva firma el ingreso, desde el inicio de sus operaciones, a una red compacta de solidaridades y contactos.

Una vez instalado el nuevo grupo de propietarios, las inversiones en infraestructura, terrenos y fábrica fueron encaradas de manera inmediata, valorizándose rápidamente el establecimiento, e incluso llegando a una escala de operaciones similar a Los Ralos. Con el tiempo, y a pesar de la fragmentación de las acciones mediante la incorporación de los descendientes de los socios fundadores, desde el seno de este grupo se desarrolló una política de relevos en la gestión que permitió mantener la estabilidad de la firma y, con el tiempo, consolidar su lógica de una empresa familiar.

Poco antes de la muerte de Brígido, ocurrida en septiembre de 1922, se introdujeron algunas modificaciones de importancia en los estatutos sociales de A\&T: se creó el cargo de "Sub-administrador", se estableció 
la periodicidad de los puestos directivos en dos años, y por último y quizás lo más importante, se conformó el "Consejo de Administración" constituido por Eudoro Avellaneda (h) como Administrador, Lauro N. Fagalde como Sub-administrador y como vocales Evaristo Etchecopar, Julio J. Cainzo y Juan Manuel Terán Vega (recordemos, hijo de Brígido). Este Consejo funcionó a modo de Directorio de la empresa, pero sin las formalidades de este último, como ser la reunión previamente estipulada mediante nota y publicación, y la confección de memorias asentadas en libros rubricados. De este modo, a través de las reuniones que muchas veces se realizaba los fines de semana, cuando se visitaba el ingenio Los Ralos, se pudo discutir sobre la marcha de la empresa y los negocios, al mismo tiempo que permitió transmitir informaciones y opiniones, sirviendo como un espacio informal de intercambio de pareceres que facilitó el mantenimiento del equilibrio en la familia- empresa. Este Consejo se mantuvo de manera invariable durante toda la existencia de la firma, con Eudoro (h) a la cabeza ${ }^{17}$.

De lo expuesto podemos concluir que desde la dirección se planificó la superación de uno de los procesos más traumáticos de la vida de las empresas familiares con administración personal: la transición de una generación a otra en los puestos gerenciales. Efectivamente, se estableció antes del fallecimiento de Brígido la nueva distribución de los socios (con la incorporación de los familiares Terán al Directorio), además del nombramiento del sucesor y el retiro del ámbito de las decisiones del antiguo Administrador. Esta conducta no sólo se dio A\&T. Brígido también estaba a la cabeza de la "Cía. Azucarera Santa Lucía" desde su fundación, actuando invariablemente como vicepresidente Evaristo Etchecopar. En este caso, también se tomó la misma actitud, retirándose del cargo de Presidente de la Compañía, y resultando como lógico reemplazante en el cargo el socio Evaristo ${ }^{18}$.

17 Archivo General de la Provincia de Tucumán (AGPT), Sección protocolos, Serie D, Tomo XVIII, fs. 19-24.

18 APJT,RPC, CM."S.A. Cía.Azucarera Santa Lucía”,Tomo XIX, 23/8/1923. (fs. 2933). En una nota otorgada meses antes de su muerte a un periódico local Brígido Terán, rememorando su desempeño frente a la firma y su posterior retiro confirmó su concepción sobre el traspaso generacional. En efecto, en la nota se afirmaba "Se retira a su hogar, después de 44 años continuos de intensa actuación, conservando el carácter de socio comanditario de Avellaneda y Terán, a cuyo directorio ingresaran su hijo don Juan ManuelTerán [Vega] y su yerno, don Lauro Fagalde.'Era tiempo-dijo a La Gaceta- los viejos 
De esta manera la sucesión generacional no habría representado un factor disruptivo en las empresas - y por lo tanto en la familia-, y significó un capital adicional de la firma al otorgarle estabilidad y cohesión en un momento en que se llevaba a cabo una estrategia de expansión y de reconversión productiva. A partir de entonces, ambas empresas no tuvieron que afrontar ningún problema de sucesión, ya que los Directorios fueron reelectos de manera invariable durante todo el período bajo estudio, lo que estaría indicando la conformidad de los accionistas sobre su desempeño y la cohesión del grupo familiar en el manejo de los negocios.

\section{Sucesión y recambio generacional}

Hasta aquí hemos visto el modo en que el control de la empresa se mantuvo dentro de la familia. Asimismo, se expusieron las estrategias de sucesión y las redes sociales que atravesaron la firma. De este modo, para nuestro caso analizado podemos hablar de una estrecha relación entre elementos familiares y empresariales que definieron las características de esta "empresa familiar". Ahora bien, si los miembros de una firma giran alrededor de una determinada actividad, cabe interrogarse hasta qué punto la imbricación de la empresa en la familia nos permite hablar de familia- empresaria ${ }^{19}$. En directa relación con lo anterior quisiéramos ajustar nuestro lente de observación en lo siguiente: ¿Es posible reflexionar sobre la naturaleza del empresariado partiendo del ámbito donde se heredan y/o desarrollan el "saber hacer", o sea, las aptitudes empresariales? ¿Se puede indagar sobre la capacidad competitiva de las empresas al tomarlas como un ámbito de reproducción de saberes empíricos sobre el manejo de los negocios?

Desde nuestra perspectiva, la transmisión interna de 'secretos' relativos a un producto o proceso productivo, a redes y contactos financieros y comerciales (que pueden ser vistos también como los conocimientos dispersos y no sistematizados presentes en los mercados o en las instituciones locales), significaban a menudo elementos clave que aseguraban

debemos ceder el lugar a los jóvenes. Es una ley natural de la vida. Reproducción parcial de la nota original publicada en un artículo conmemorativo en: La Gaceta, 27/08/1972.

19 Dos excelentes trabajos donde se aplica el concepto de familia-empresa pueden consultarse en (CERUTTI, 2000) y (REGUERA, 2006). 
la continuidad en un negocio y, por consiguiente, representan un tema estrechamente relacionado con el de la sucesión o transmisión intergeneracional de la empresa ${ }^{20}$. Este punto es central, pues en muchos casos suele manifestarse la resistencia de los "viejos hombres de empresa" para dejar los negocios, lo que se combina con la falta de experiencia de los herederos en el manejo de la firma una vez que deben hacerse cargo de la misma.

En efecto, se ha sugerido que la corta vida de las empresas familiares tiene una de sus mayores causas en el fracaso de los líderes por planear la sucesión. En este tipo de firmas el proceso de garantizar el cambio generacional está plagado de conflictos y puede representar el elemento más traumático que enfrentan las empresas familiares (BOZZO,1999: 59; COLLI, FERÁNDEZ PÉREZ, ROSE, 2003:33-34). Como advirtió Mary Rose:

La transmisión del liderazgo de una generación a otra es una de las experiencias más agónicas a la que se enfrenta cualquier actividad. Como un shock interno en la firma, es también una prueba crítica para el espíritu de empresa (...) los empresarios legan a sus sucesores una herencia empresaria. Esta herencia incluye el activo de la firma, tecnología, contactos, reputación, etc., y un plan para asegurar la sucesión (ROSE, 1993:128).

En nuestro estudio de caso, la reproducción de 'aptitudes empresariales' parece no haber estado ausente, aunque lógicamente sus manifestaciones resultan difíciles de rastrear. Sin embargo, repasando el derrotero de Eudoro (h) podemos apreciar cómo se lo involucró de manera temprana en el ámbito empresarial. En efecto, en 1903, una vez finalizados sus estudios en leyes en la ciudad de Buenos Aires y tras su regreso a la provincia, Brígido lo incorporó a la gestión de la empresa, desempeñándose a partir de entonces como su "mano derecha" en calidad de Sub Administrador de hecho ${ }^{21}$. Posteriormente pasó a formar

20 Como sostiene Mark Casson, preparar, educar, enseñar sería una de las ventajas comparativas reconocidas que, en algunos sectores de actividad, tendrían las empresas familiares sobre las no familiares. Véase (FERNÁNDEZ PÉREZ, 2003:59).

21 Esta colaboración y división de tareas entre Brígido y su sobrino Eudoro (h) puede constatarse a través de diversos testimonios de la época, y se comprueban en las Actas de las Asambleas de Accionistas a partir de 1908.Véase por ejemplo Álbum de la Provincia de Tucumán, 1910: s/n; La Nación (Edición Especial del Centenario, 1916:s/n). 
parte del Consejo Directivo y, por último, a desempeñarse como Presidente de la firma. Un derrotero similar puede observarse en Juan M. Terán Vega y Lauro N. Fagalde, quienes primero se integraron a la firma como socios comanditarios, para luego formar parte del Consejo en carácter de socios solidarios. Asimismo, cada uno de los socios tuvo participación en otros emprendimientos empresariales, ya sea como accionistas o dentro del ámbito gerencial22.

Empero, no nos encontramos ante un caso aislado. Si realizamos una mirada general sobre el desenvolvimiento de las empresas azucareras familiares tucumanas en el período estudiado, se puede concluir que, en líneas generales, el manejo de los negocios se mantuvo en manos de los socios primigenios y sus descendientes. Aunque esta tendencia no fue privativa de los empresarios del sector, pudimos constatar que en varias empresas azucareras tucumanas, ya fueran colectivas o de propiedad individual, tarde o temprano se asistió a la incorporación de familiares en el ambiente azucarero antes del traspaso generacional y, en este sentido, podemos conjeturar que, de un modo u otro, la sucesión estuvo implícitamente planteada.

De este modo, podemos mencionar los casos de las firmas "Paz y Posse" (ingenio San Juan), "Rougés y Rougés" (ingenio Santa Rosa), la S.A. "Padilla Hnos.” (ingenio Mercedes), “Justiniano Frías y Cía.” (Ingenio

22 Por razones de espacio no podemos detallar la participación de cada uno de los socios en diferentes empresas. Sólo a título ilustrativo podemos mencionar que los integrantes de A\&T participaron de otros emprendimientos de manera conjunta, alternando sus puestos sin una correspondencia con el aporte del capital. De este modo, Evaristo Etchecopar fue quien estuvo al frente de la "Cía. Azucarera Santa Lucía”, sin poseer el mayor número de acciones; de igual manera Lauro N. Fagalde estuvo al frente de "Fagalde y Cía. Sociedad Agrícola y Ganadera", firma donde participaban todos los socios analizados. También se extendieron al ámbito de las finanzas, participando del "Banco Constructor de Tucumán”, donde Brígido Terán y posteriormente Juan Manuel Terán Vega, ejercieron la presidencia (éste último también formó parte del Directorio del "Banco Comercial del Norte", otra de las entidades financieras más sobresalientes de la plaza tucumana). Por otra parte, se vincularon con miembros de otras familias azucareras a través de sociedad "El Fénix del Norte, Compañía de Seguros”, donde se vincularon con Alfredo Guzmán (ingenio Concepción), Ramón Paz Posse (ingenio San Juan), Carlos Rougés (Ingenio Santa Rosa), entre otros. Asimismo cada uno de los miembros llevó adelante emprendimientos particulares, en la mayoría de los casos haciendo participar a sus descendientes. 
San José), Juan M. Terán (ingenio Santa Bárbara), entre otros ${ }^{23}$. También se cuentan ejemplos en que los descendientes combinaron las funciones directivas con la dirección técnica de las fábricas, como en los casos del ingeniero Manuel García Fernández (h), (ingenio BellaVista); el ingeniero Enrique Simón Padrós, de la firma "Simón, Padrós, y Cía." (ingenio Aguilares); y el reconocido ingeniero Luis F. Nougués (ubicado dentro de la tercera generación de socios familiares), no sólo al frente del establecimiento, sino como Gobernador de la provincia y como co-fundador de la Estación Experimental Agrícola de Tucumán, la primera institución científica en el país al servicio de una actividad productiva ${ }^{24}$.

De esta manera, no sólo pudimos observar un interés por preparar a las nuevas generaciones en el manejo de los negocios, con su incorporación en las labores administrativas, sino que en ciertos casos se vio la especialización de los sucesores en el aspecto industrial para el manejo y supervisión directa del establecimiento azucarero. Estos elementos estarían indicando que la reproducción de las aptitudes empresariales habría estado presente en la mente de algunos industriales del sector. Si a esto le sumamos que en muchos casos existió una práctica de visita periódica a los establecimientos, como una forma de interiorizarse con el personal de fábrica y escritorio sobre los pormenores del ingenio, la imagen social fuertemente instalada de los empresarios azucareros tucumanos como propietarios "ausentistas" quedaría, por lo menos en la primera mitad del siglo XIX, fuertemente cuestionada ${ }^{25}$.

23 APJT,RPC, CM, "Paz y Posse”Tomo IV,15/3/1888. fs. 247-251; "Rougés y Rougés", Tomo VII, 18/10/1907. fs 22-24; “Padilla Hnos.”, Tomo VI, 29/8/1906. fs. 265-275; La participación de los sucesores Frías en el ingenio San José puede acreditarse en diversas publicaciones, como en el (Álbum Argentino, 1910:s/n). En el caso de Juan M. Terán (propietario del ingenio Santa Bárbara), su primogénito Juan Benjamín Terán (fundador de la Universidad de Tucumán e importante político e intelectual tucumano) y sus yernos Domingo Colombres y Marcos Rougés (ambos casados con sus hijas, y el último socio propietario del ingenio Santa Rosa) tuvieron una activa participación en los negocios del ingenio, aunque en este caso se mantuvo hasta la muerte de Juan M.Terán como un emprendimiento de propiedad individual.

24 (Padilla, 1922: 305); APJT, RPC, CM, "Simón, Padrós y Cía", Tomo XVIII, 1922. fs 1-13; (Schleh, 1944:84); (Nougués: 1976).

25 Sobre las visitas periódicas y la discusión de la marcha de los negocios con el personal de planta, poseemos datos concretos que muestran una práctica extendida llevada a cabo por las familias Frías, Avellaneda, Terán, Nougués, Rougés, Simón Padrós, Paz y Posse, entre otras. 
Si bien no se pueden realizar generalizaciones al respecto (además de no poseer datos concretos sobre el desempeño en los negocios de las nuevas generaciones), creemos factible este tipo de aproximación, la que necesariamente deberá complementarse con estudios comparativos, tanto a nivel regional como interregional ${ }^{26}$.

\section{La propiedad y dirección de la firma}

\section{La diferentes formas societarias}

Si se analiza la estructura de la propiedad de los ingenios azucareros en el Censo de 1895, podemos comprobar que de las 33 unidades fabriles existentes en la provincia, el 52\% correspondía a las familias azucareras provenientes de la elite tucumana, el 29\% a propietarios de origen extranjero (que en muchos casos habían realizado la acumulación del capital en la provincia), y el 19\% restante a inversores extrarregionales. Pero quizás lo más significativo para nuestro estudio sea la existencia de sólo tres Sociedades Anónimas (S.A.), siguiendo 11 Sociedades Colectivas y una Sociedad en Comandita. Esto evidencia que a finales del siglo XIX, la forma de posesión más difundida en el complejo azucarero tucumano era la propiedad individual y la sociedad familiar con responsabilidad solidaria.

26 A modo de aproximación, en el complejo azucarero saltojujeño se puede observar un derrotero similar, por lo menos entre las dos empresas más importantes de la época: la firma "Leach Argentine Estates, Ltd.", propietaria del ingenio La Esperanza, y la empresa "Ledesma Sugar Estates and Refining $C^{\circ}$, Ltd.", propietaria del ingenio homónimo. Aunque se trataron de Sociedades Anónimas abiertas, que cotizaban en Bolsa, el control y la propiedad se situaron mayormente en el núcleo familiar: los Leach en el primer caso, y la sucesión familiar Wollmann-Arrieta-Blaquier, en el segundo. Los hermanos Leach circularon en diferentes puestos de la empresa, desde la administración directa y supervisión técnica del ingenio, hasta los cargos directivos en los Consejos de la Compañía en Buenos Aires y en Londres. Empero, no poseemos datos referentes al desempeño de su descendencia. En el caso de Ledesma, es clara la vinculación previa de la sucesión familiar "política" en los negocios azucareros, teniendo temprano protagonismo y luego comandando la empresa el yerno del Enrique Wollmann, Herminio Arrieta y posteriormente su yerno Carlos Pedro Blaquier. Hasta el presente, sus descendientes ocupan los cargos directivos y poseen la mayor parte del paquete accionario de la firma.Véase (SCHLEH, 1944: 184), (LEDESMA, 2008 : 63,92), (PADILLA, 1922: 339-322), (SIERRA IGLESIAS, 1998). 
Pero el panorama cambió durante los años del cambio de siglo, con el incremento en la actividad de la forma societaria más extendida en los países industrializados, la Sociedad Anónima, en consonancia con un proceso más general desarrollado en el país antes de la primera guerra mundial (LEWIS, 1993:101; ROCCHI, 2006:190).

De todas maneras, aunque esta tendencia a la reconversión societaria ciertamente ocurrió, en un principio no se trató de un proceso generalizado, sino que se centró principalmente entre los ingenios con sus finanzas comprometidas producto de la primera crisis de sobreproducción. En efecto, durante estos años se produjo el mayor movimiento societario, con una serie de fusiones, reconversiones y liquidaciones de firmas azucareras. La saturación del mercado había provocado una caída significativa de precios, lo que puso en graves aprietos a los propietarios de ingenios que se habían endeudado o hipotecado sus propiedades con el fin adquirir maquinarias y tierras. De este modo, varias empresas quebraron y sus ingenios cerraron bien por deudas o por no haber podido ingresar dentro del proceso de reconversión tecnológica ${ }^{27}$ (CAMPI y BRAVO, 1997).

En este período y hasta mediados de la década de 1910, podemos observar que de 12 formaciones de S.A. en la agroindustria, sólo tres correspondieron a la continuidad de las familias en las empresas, mientras que las demás se formaron exclusivamente para ingresar al negocio azucarero, aunque en su mayoría tuvieron una corta vida ${ }^{28}$. De este modo, se conformaron Sociedades Anónimas azucareras mediante el ingreso de los acreedores como propietarios luego de un arreglo con los titulares de las firmas, o bien con la ejecución y pase de la propiedad a

27 El caso paradigmático de fusión de sociedades ocurrió en 1901, con la incorporación de la "S.A. Ingenios Río Salí" (propietaria de dos ingenios) a la CAT, de modo que esta corporación controló, a lo largo de todo el período analizado, cinco unidades fabriles. Por su parte la "Cía.Azucarera Concepción”, que le siguió en importancia, fue el resultado de la reconversión de “Guzmán y Cía." en S.A., con la incorporación de capitales extrarregionales, aportados por la familia Paz.

28 Entre ellas podemos mencionar a la "Compañía Azucarera Cordobesa" (1897); S.A. "Ingenio San Miguel” (1901); S. A.” Azucarera del Norte” (1902); “Cía. Azucarera El Paraíso" (1903); Cía.Azucarera "El Fénix” (1910); "Ingenio Azucarero GermanoArgentino S.A" (1912). Estas empresas evidenciaron derroteros diferentes, poniendo fin a sus operaciones tras algunos años en la actividad. Sólo la última SA mencionada logró mantenerse por varios años en la agroindustria tucumana. 
sociedades constituidas ad hoc. De todas formas, resultaba notoria la fuerte persistencia de las familias azucareras tucumanas durante la década de 1910.

En el Censo de 1914 figuraban 19 ingenios pertenecientes a SA, cuatro a colectivas, tres a comanditas y cuatro a particulares. Empero, atendiendo al número de unidades que molieron en el año del relevamiento (1914) y su identificación individual de acuerdo al cruce de información con documentos del Registro Público de Comercio, podemos comprobar la inexactitud de los datos censales. Una vez corregidas las cifras, el número de ingenios que pertenecían a SA se redujo a 11 , mientras que cinco correspondían a colectivas, cuatro a comanditas, y seis a particulares.

Una vez determinado el número de ingenios y su razón social, optamos por cruzar esta información con los datos de la producción de 1914. A partir de esta operación, se comprobó la primacía de las Sociedades Anónimas en la producción tucumana de azúcar, con una participación del $67 \%$, mientras que correspondió a las Colectivas el 8\%,y a las Comanditas e ingenios de propiedad individual, el 13\% cada uno. Empero, si realizamos una distinción entre los ingenios sobre la base de su pertenencia a capitales foráneos, mixtos (con participación tucumana) y netamente locales, el cuadro de la situación se modifica, correspondiendo el 48\% de la producción a capitales tucumanos (más allá de la razón social de sus firmas), el $30 \%$ a capitales mixtos y el 22\% a foráneos.

Por lo tanto, es posible concluir que a pesar de la tendencia a la reconversión en Sociedades Anónimas, y la leve disminución del núcleo de empresas correspondientes a capitales tucumanos, la participación de las empresas de capital local en la producción total de la provincia resultó mayoritaria, contradiciendo la supuesta "extranjerización" de la actividad al iniciarse el siglo XX (SANTAMARÍA, 1986:18-19) ${ }^{29}$.

Ahora bien, ¿qué tipo de ventajas reportaba la constitución de una SA? Principalmente, permitía apelar a los ahorros de potenciales inversionistas proporcionando, a la vez, la protección de la responsabilidad limitada, la cual recaía sólo sobre el monto de las acciones que se poseía.

29 Este cálculo se realizó sobre la base de la participación en la producción total de los ingenios, según las cifras consignadas en el Anuario Estadísticos de la Provincia para la zafra de 1914, año que coincide con el relevamiento del Censo. 
De este modo, mientras otras sociedades podían crecer sólo reinvirtiendo sus utilidades o incorporando nuevos socios para no generar endeudamiento, las Sociedades Anónimas podían obtener financiamiento externo a través de la venta de títulos de deuda o con la emisión de acciones (SIBURU, 1923).

Sin embargo, a pesar del incremento evidente de la participación de la SA en la agroindustria tucumana, en líneas generales, su presencia en la actividad económica del país resultaba muy reducida, siendo eclipsada por las diferentes formas de asociación familiar. Esta situación fue resaltada expresamente en el Censo Nacional de 1914 (MARTÍNEZ, 1919:9-15).

Sobre este punto, Paul Lewis, en su ensayo sobre el derrotero seguido por el capitalismo en Argentina, destacó la fuerte reticencia por parte de los industriales locales a abrir sus firmas a personas ajenas a la familia, en el temor que se diluyese su control personal de las mismas. Por lo tanto, los empresarios argentinos habrían antepuesto la "lealtad familiar" en detrimento de la eficiencia, las ganancias y el crecimiento. En definitiva, de acuerdo a la visión de este autor: "El hecho de que el capitalismo argentino se basase en grupos familiares contribuyó a que la Bolsa de Valores de Buenos Aires no pudiese llegar a ser un mercado eficaz de capitales (...) Así, a diferencia de lo acontecido en otros países en su proceso de industrialización, los inversores argentinos fueron siempre tradicionalistas y conservadores" (LEWIS, 1993:107).

Difícilmente se pueda obviar la consideración negativa de las empresas familiares al concebirlas como un elemento anacrónico y retardatario de la modernización. En general, para estas posturas, la restricción de la propiedad y el control de las firmas a un grupo de parientes representan un escollo en el sistema de mercado, puesto que restringía los mecanismos de financiación y expansión de la producción. Además, desde esta óptica, las empresas familiares, al operar en escalas menores a las grandes corporaciones, alientan la reinversión de utilidades y esquivan el mercado bursátil o la financiación a largo plazo (FERNÁNDEZ PÉREZ, 2003:51).

Pero a pesar del marcado posicionamiento y juicio de valor sobre el desempeño de las firmas familiares en el desarrollo económico, la falta de concurrencia al mercado de valores por parte de los empresarios argentinos durante la primera mitad del siglo XX, y el fuerte peso 
del elemento familiar en la sociedades fabriles argentinas, representaron datos ineludibles de la estructura empresarial general ${ }^{30}$.

De todas maneras, y siguiendo la propuesta de estudiosos europeos como Colli, Fernández Pérez y Rose; y latinoamericanos como Cerutti, convendría encuadrar el análisis sobre el rol desempeñado por las empresas dentro de sus propios contextos regionales, en el sentido que el peso y la evolución de las empresas familiares durante los procesos de industrialización temprana resultaron indisociables del entorno económico, los antecedentes institucionales, las actitudes hacia la familia y sus miembros, y la cultura de la comunidad empresarial local (COLLI, FERNÁNDEZ PÉREZ, ROSE, 2003: 28-64; CERUTTI, 2000: 109).

A pesar de ciertas modificaciones en sus formas jurídicas, un segmento importante de firmas azucareras tucumanas logró mantener durante todo el período bajo estudio la propiedad y el control en manos de los antiguos socios, que en su mayoría eran familias descendientes del fundador. Sólo a partir de 1906 algunos empresarios azucareros de raigambre local dieron el paso a la reconversión de sus empresas familiares en SA aunque, como veremos, se trató básicamente de una estrategia empresarial.

En efecto, no todas las conversiones en sociedades anónimas terminaban en una pérdida de control por parte de los socios propietarios. En general, durante los procesos de industrialización incipiente las empresas solían utilizar este tipo de mecanismos jurídicos con el objeto de reunir una mayor suma de capitales, o bien resguardarse contra posibles causas judiciales, mediante la limitación de la responsabilidad de los asociados sobre el capital ${ }^{31}$.

30 Según afirma Rocchi, a diferencia de lo que tradicionalmente se supuso, el fracaso del Mercado de Valores en relación al impulso de la industria no radicó en la falta de interés por parte de los empresarios por buscar financiamiento, sino en las pocas oportunidades que proporcionaban a los inversores. Véase (ROCCHI,2006:194); (GUY, 1982:362).

31 Sobre este punto, Harold James, discute la noción de la empresa familiar como una mera fase transitoria de organización comercial cuyo destino ineluctable es ser suplantada por la corporación moderna. Ciertamente, mostró que el formato de empresa con responsabilidad limitada (SA) durante el siglo XIX y buena parte del XX en Europa, fue una herramienta estratégica de las empresas de tipo familiar, para ser utilizada o bien descartada cuando las circunstancias lo requirieron (JAMES, 2006). 
Autores como Guy sugirieron que las transformaciones societarias acaecidas a comienzos del XX estuvieron motivadas por las crecientes necesidades de financiamiento de las firmas. En este sentido, la formación de Sociedades Anónimas habría permitido a los industriales tucumanos acceder a otras formas de capitalización, mediante la apelación a los ahorros de pequeños inversores que pudieron ingresar al rubro a través de la compra de acciones (Guy, 1981:139). Desde una perspectiva también centrada en la necesidad de financiamiento, Sánchez Román interpretó la formación de Sociedades Anónimas en la actividad azucarera tucumana como una vía de capitalización, advirtiendo además que la constitución de una SA no representaba la automática pérdida del control de la empresa, en tanto la clave del proceso residía en cambiar la forma jurídica sin abrir la transacción pública de la acciones (Sánchez Román, 2005a: 316-317) $)^{32}$.

Otra explicación sobre la tendencia a la reconversión en SA se centró en las ventajas que reportaba la adopción de esta forma jurídi$\mathrm{ca}$, al reducir los niveles de compromiso del empresario con el capital y resguardar, de este modo, su patrimonio personal (GALLO, 1902: 383; GUY, 1981: 139).

Más allá de las diferentes interpretaciones, desde nuestro punto de vista no consideramos que la búsqueda de financiamiento fuera la razón que condujo de manera excluyente a la adopción de esta forma legal, por lo menos en lo que se refiere al segmento de empresarios azucareros tucumanos. Podemos conceder que la limitación de la responsabilidad representaba un elemento seductor para cualquier inversor, pero no necesariamente la emisión de acciones fue la vía de capitalización.

Ocurre que en un "capitalismo de corte familiar" como el que se conformó en torno a esta actividad, el peso de los lazos familiares incidieron a la hora de permitir el arribo de inversores foráneos por medio de la suscripción de acciones ${ }^{33}$. En muchos casos, se estipuló en el con-

32 Aunque en un principio el autor afirma que la opción corporativa permitía el acceso a la capitalización mediante nuevos inversores, más adelante, señala que sólo 7 de 19 sociedades azucareras argentinas ofrecían sus acciones en la Bolsa en 1914. Véase (SÁNCHEZ ROMÁN a, 2005: 317). De manera nada casual, ninguna de estas empresas correspondía al segmento de industriales azucareros tucumanos.

33 Sobre la utilización del concepto de capitalismo familiar, véase (CERRUTI, 2000); (JAMES: 2006). 
trato social la prohibición de la libre transacción de las acciones, o bien se procuró repartir títulos nominales no endosables. En otros, se impidió de manera más solapada el arribo de foráneos a través de disposiciones estatutarias en las que los socios primigenios tenían preferencia a la hora de la venta de acciones, o bien, se permitía su ingreso luego de la aprobación del Administrador de la empresa o el Directorio, es decir, de la cabeza de la familia propietaria.

Este camino fue seguido por varias familias tucumanas (y en general por los empresarios industriales argentinos), mediante la conformación de las denominadas "sociedades anónimas de familia", o sea las S.A. cerradas, en oposición a las S.A. abiertas, que operaban con oferta pública y cotizaban títulos en Bolsa ${ }^{34}$ (VERÓN, 1968: 24); (LEWIS, 2003:105).

Las S.A. familiares conformadas durante este período fueron la "Cía. Azucarera Padilla Hnos.”, (1906); "Cía. Azucarera Wenceslao Posse”, (1907) y "Cía.Azucarera Santa Lucía”, (1908) que a pesar de no haber nacido de una familia, se conformó a través de la unión de varios empresarios azucareros, vinculadas entre sí por lazos parentales y amicales. ${ }^{35}$ Sin embargo, en el transcurso de las siguientes décadas se sumaron a esta figura jurídica las empresas familiares S.A. "San Pablo, de fabricación de azúcar”, (1920); “Cía. Azucarera Bella Vista, García Fernández”, (1923); “Cía.Azucarera Juan Manuel Terán”, (1926); “Paz \& Posse Ltda. Ingenio San Juan”, (1926); “Cía. Azucarera Guillermo Hill”, (1930); “Cía. Azucarera Ingenio Amalia”, (1932);“Cía.Azucarera Justiniano Frías”, (1935), entre otras ${ }^{36}$.

34 La 'SA Cerrada' son aquellas que comúnmente se denominan 'de familia', o sea las que no recurren a la suscripción pública de acciones y mantienen el capital en manos de un grupo familiar, de amigos, o simplemente, en núcleo de personas que $a b$ initio tuvieron la idea de mancomunarse en el esfuerzo de emprender una actividad económica. (VERÓN, 1969: Exordio).

35 APJT, RPC, CM, “Padilla Hnos”, TVI, 1906. (Fs 265-275); “Paz y Posse”TVI, 1907 (Fs. 462-487); Santa Lucía”TVI, 1907. (Fs. 415-428)

36 En 1920 se desdobló "Nougués Hnos" en la "C ${ }^{a}$ San Pablo de Fabricación de Azúcar S.A.” y la S.A.” Comercial, Financiera y Ganadera Nougués Hnos Ltda."Véase (SCHLEH, 1944:79); (NOUGUÉS, 1976: 221); APJT, RPC, CM, "Bella Vista” Tomo XIX, 1923. fs. 1-14; "Juan Manuel Terán”, Tomo XXII, 1926. fs. 197-214; “Paz \& Posse”, Tomo XXII, 1926. fs. 214-237; “Guillermo Hill”, Tomo XVIII, 1930. fs. 351-386; “Amalia”, Tomo XXX, 1932. fs. 295.323; “Justiniano Frías”, Tomo XXV, 1935. fs. 40-71. 
En todos los casos se produjo la incorporación a la empresa de parientes políticos y sanguíneos. Además, no es ocioso señalar que los que conformarían la cabeza de las SA poseían en su haber una vasta experiencia como administradores de los establecimientos, representando, en cierto modo, el centro operativo de las empresas. En definitiva, si estas familias adoptaron la forma jurídica S.A., no funcionaron de hecho como 'sociedades' (por la fuerte impronta personalista del propietario o de los administradores), ni fueron 'anónimas' o públicas en el sentido estricto del término (pues si el capital social fue dividido en acciones, éstas permanecieron cerradas a la transacción pública, manteniendo de manera firme el paquete accionario dentro de los límites familiares).

Ante este panorama, surge una pregunta obligada, y es por qué se optó por esta forma asociativa siendo que se podían continuar las operaciones bajo las figuras organizacionales anteriores. La muerte o separación de un socio, no llevaba indefectiblemente a la liquidación de la sociedad, en tanto las firmas podían disolverse parcialmente o incorporar nuevos socios (los herederos), sin necesidad de cambiar su figura legal. Entonces, ¿qué motivó a los integrantes de estas empresas familiares a continuar las operaciones bajo una figura jurídica diferente?

Sin dudas, resulta sumamente complicado establecer en todos los casos los elementos sopesados por las familias para la conversión de una sociedad colectiva o comandita en SA. Por otra parte, no fue habitual que se asienten por escrito las consideraciones previas a esta elección. De acuerdo a las escrituras de constitución de las sociedades, pudimos ubicar algunas razones, entre ellas, la intención de mejorar la organización interna, asegurar la continuidad de la sociedad tras la muerte de un socio, o bien para resguardar el patrimonio de los menores de edad.

De todos modos, los escasos datos sobre ofrecimiento de acciones a personas ajenas al núcleo familiar y la casi nula oferta en la Bolsa de Comercio, nos llevan a pensar que la formación de SA obedeció más a una fórmula atractiva para limitar los riesgos, y en su mayoría, mantener la propiedad y el control dentro del núcleo familiar. Esto, como vimos, se lo pudo concretar a través de la conformación de las denominadas "sociedades anónimas de familia" o sea las SA "cerradas". 
Como podemos observar, la propiedad y el control de la firma representaban, para los miembros de la misma, parte del acervo familiar, algo imposible de medir, pero con gran peso en las decisiones (COLLI y ROSE: 2003). En este sentido, como observó Sapelli, los factores culturales juegan un rol determinante dentro del devenir de las empresas, en tanto la familia “(...) más que cualquiera maximizan la confianza y la reciprocidad (que como es notorio, se pesan y no se cuentan)" (SAPELLI, 1996:35).

Pero si esta explicación nos permite comprender la conversión de SA familiares, tendencia que se acentuó con el transcurrir de los años, todavía nos resta explicar por qué motivos un amplio segmento de empresarios y familias azucareras, como Avellaneda \& Terán, mantuvieron sus firmas dentro de estructuras organizativas más simples, con responsabilidad solidaria.

Sobre este punto, conviene sopesar otro tipo de explicaciones que trasciendan los límites netamente económicos o utilitarios. En la literatura especializada, las empresas familiares han sido interpretadas en contextos de incertidumbre externa e inestabilidad de los mercados, como una institución que aglutinó una red de confianza y valores compartidos. Cuando los objetivos de la familia y la empresa estuvieron unidos, las redes de confianza tuvieron la ventaja de garantizar a todos sus miembros una combinación de incentivos, un control eficaz, y la protección contra el peligro de irregularidades de gestión (COLLI, FERNÁNDEZ PÉREZ, ROSE, 2003:33).

Esto bien puede ser aplicable a las empresas tucumanas de propiedad individual o integradas por socios solidaria e ilimitadamente responsables de la suerte de la empresa. En estos casos, para el o los socios responsables de la administración, la suerte en los negocios era vista esencialmente una extensión de sí mismo. De ahí el compromiso de buscar el mejor resultado posible para favorecer la buena marcha de los negocios, que en definitiva redundaba en el bienestar familiar. Por otra parte, la fuerte impronta personalista y la gran maleabilidad de la gestión en empresas de este tipo (a diferencia de las pesada organización de las SA, compuestas por Directorios, Juntas, Asambleas, etc.) permitían a las cabeceras de familia, sobre todo en momentos de crisis, realizar una serie de movimientos impensados en otro tipo de estructuras organizativas (GARCÍA LÓPEZ, 1994:181). 
De este modo, se podía plantear el pase de utilidades a reservas o pagos, la retención de dividendos, incluso apelar al ahorro personal de los socios, aportando efectivo a la empresa a cambio de un cierto interés, para salir del paso sin apelar al endeudamiento externo que pusiera en riesgo la estabilidad de la firma. En este sentido, la gran adaptabilidad de las empresas familiares habría jugado como un factor adicional a su favor en momentos de crisis, y que bien podrían hacerse extensivos a un amplio segmento del empresariado tucumano.

En algunos casos hemos podido advertir la transformación de las sociedades familiares de tipo colectivas e comandita por acciones.Varias empresas pertenecientes a las familias Frías (San José), Paz y Posse (San Juan), Nougués Hnos. (San Pablo), Avellaneda y Terán (Los Ralos), entre otras optaron por mucho tiempo por esta forma "híbrida" de asociación, que dividía a los socios por la responsabilidad ante el capital y el derecho a la gestión de la firma. Aunque también aquí resulta difícil hallar motivos explícitos sobre esta operación, podemos encontrar, sin embargo, algunas regularidades.

En un primer lugar, podemos mencionar que los antiguos socios encargados de la administración de la empresa mantuvieron sus cargos, participando en la nueva razón social en calidad de socios solidarios. Esto, claro está, los hacía totalmente responsables en relación al devenir de la firma. Los socios que ingresaron en calidad de comanditarios fueron las herederas mujeres de los fundadores o los herederos varones menores de edad. De esta manera, se asociaban a la firma a través de su derecho hereditario, resguardando su responsabilidad solamente al capital aportado.

Por otra parte, podemos detectar el apartamiento de las mujeres de las esferas de la gestión, ingresando, en todo caso, sus esposos aunque estas poseyeran una alta proporción del paquete accionario. Este mecanismo, como sugerimos, podría explicarse por el modelo tradicional de empresa familiar, notoriamente patriarcal y personalista, que reservaba los puestos gerenciales a los descendientes varones, quienes deberían incorporarse como "mano derecha" del fundador dentro del esquema familiar de la empresa. De todos modos, son necesarios mayores esfuerzos investigativos para desentrañar este tipo de lógicas.

Sin embargo, no debemos pensar que las mujeres no cumplieron un importante rol en el esquema familia-empresa. Directa e indirectamente, 
se desempeñaron como fuentes primordiales de contactos a través del matrimonio como una forma eficaz de reducir los costos de transacción mediante la ampliación de la red familiar de confianza. De mismo modo, y ante el marco legislativo que imponía la herencia divisible en lugar de la primogenitura, los matrimonios entre familiares a menudo eran un instrumento para contrarrestar la dilución de la riqueza familiar, así como fortalecer y ampliar las redes sociales (HERRERA, 2007).

En definitiva, si en algunas familias azucareras se optó por la SA como forma de resguardarse de los posibles inconvenientes financieros a través de la limitación de la responsabilidad; en otros casos, se mantuvieron las estructuras tradicionales de organización, manteniendo la responsabilidad solidaria de sus miembros. En estos últimos, y al igual que muchos países en las etapas tempranas de la industrialización, la responsabilidad solidaria e ilimitada resultó atractiva precisamente porque pesaba como un elemento de disuasión a posibles maniobras especulativas de los encargados de la gestión. ${ }^{37}$ Además, cuando se produjo la incorporación de parientes políticos en la gestión de la empresa (en representación de las mujeres con participación en las acciones), su responsabilidad en la empresa pasó a calidad de solidaria e ilimitada, alejando los peligros de posibles desavenencias por parte de estos nuevos integrantes, en resguardo de la empresa, y por los tanto, de la familia.

Retomando nuestro análisis de caso, en oposición a la tendencia general que siguieron las firmas azucareras tucumanas durante las primeras décadas del siglo XX, "Avellaneda \& Terán” fue una de las últimas en convertirse en sociedad anónima. ¿Qué razones específicas podrían haber inducido a los propietarios a apartarse de este camino y mantenerse como sociedad en comandita?

Como respuesta tentativa, y de acuerdo a las condiciones del ambiente, se podría suponer que la serie de obligaciones que el Código de

37 La responsabilidad ilimitada se convirtió en un elemento inseparable de la cultura de las empresas familiares en Gran Bretaña durante la mayor parte del siglo XIX. Ella proporcionó una protección contra la especulación y reforzó la tendencia de incorporar como socios solo a aquellos procedentes de familias cercanas, con conexiones personales, $\mathrm{u}$ otros con los valores y perspectivas compartidos. Los empresarios en España e Italia también se mostraron reacios a limitar la responsabilidad mediante el uso de Sociedades Anónimas (COLLI, FERNÁNDEZ PÉREZ, ROSE, 2003:32-33). 
Comercio imponía a este tipo de sociedades, que iban desde la presentación y publicación periódica de las Memorias y Balances de las empresas en las Oficinas de Justicia, hasta la auditoría contable de la misma, alejó esta opción. Quizás hayan jugado un rol el recelo por mostrar los resultados de los negocios a través de la publicación obligatoria de balances y memorias. Por otra parte, las relativamente buenas perspectivas que todavía ofrecía la actividad a comienzos del siglo XX no habrían hecho imperiosa la necesidad de limitar la responsabilidad de los socios en una firma que venía siendo manejada satisfactoriamente.

Sin embargo, queda una arista por analizar y es la injerencia que tuvieron, por lo menos en este caso, las redes de familia dentro de la firma. Como sostiene Mary Rose (1993:128), “(...) la estrategia de negocios de las firmas de familia no puede ser explicada de una manera puramente centrada en la empresa. En cambio, es necesario mirar a las redes familiares, de negocios y a veces religiosas dentro de la cual la firma opera. Esto fue cierto desde una perspectiva de las finanzas, pero también con respecto a la selección de sus compañeros"). La incorporación dentro de posiciones directivas de los socios en A\&T no implicó una disputa por la conducción de la misma. El mantener la firma dentro de un núcleo pequeño, cruzado por lazos parentales fuertemente instalados, habría permitido a los responsables de la dirección contar con un "voto de confianza" por parte de los demás accionistas en el manejo de los destinos de la empresa. Esto se evidenció en la larga permanencia que tuvieron sus dos presidentes, Brígido Terán y Eudoro Avellaneda (h), siendo el segundo reelecto invariablemente. Esta confianza le habría permitido el consenso al afrontar políticas expansivas con cierto nivel de riesgo o, por ejemplo, optar por el financiamiento interno mediante la retención de dividendos, no sólo en momentos de dificultad, sino en períodos de amplias ganancias, con la consiguiente privación de los socios de los beneficios generados por sus acciones.

Este tipo de maniobras, si bien se realizan en empresas con tipos societarios distintos, la negociación suele ser dificultosa donde en la unión de las personas priman los intereses económicos. Esto no quiere decir que las relaciones dentro de la empresa fueron armónicas en su totalidad, ya que existe evidencia de algunas desavenencias. Pero sí podemos dejar sentado que la planificación de la sucesión y la consolida- 
ción de lazos en la familia en el manejo de los negocio jugaron un rol determinante, por lo menos en este caso estudiado.

De manera tal que la política seguida de mantener la propiedad y la gestión de la empresa en la familia, junto con una estrategia de integración productiva (que le asegurara una mayor autonomía y menores costos de producción), y una gestión satisfactoria, podrían explicar por qué la firma no siguió la tendencia general de transformación en SA hasta fines de la década de 1940.

Aunque no podamos otorgar una respuesta lo suficientemente explicativa sobre por qué no se resguardaron los intereses detrás de una razón social diferente, el hecho de no haber sido los únicos dentro del sector, permite suponer el carácter patrimonial que tuvieron las empresas para algunas familias azucareras y la identidad de grupo que generaron sus miembros de las familias ${ }^{38}$. Es preciso indicar, sin embargo, que tanto la tendencia a la conformación de S.A. familiares, como la resistencia de algunos empresarios a tal reconversión, tuvieron lugar entre el empresariado argentino de la época (LEWIS, 1993: 94-108). Solo mayores esfuerzos investigativos podrán permitirnos comparar las estrategias de preservación del patrimonio familiar y dilucidar las razones por las cuales se prefirió el mantenimiento de esta organización familiar-empresarial.

\section{La estructura de gobierno}

Existen diversas formas de organización en las empresas, en gran medida están determinadas por el tipo de producto, la complejidad del proceso productivo y por otros factores "inmateriales", como las pautas culturales e idiosincrásicas de cada región. Empero, se reconocen dos tipos básicos de dirección en empresas de mediana complejidad. Por un lado, se encuentra el empresario que se involucra en el conocimiento del negocio y su evolución de forma personal, apoyán-

38 En este sentido, podemos mencionar a los Simón Padrós, que explotaron en el ingenio "Aguilares" a través de una sociedad en comandita, y más adelante el ingenio "San Ramón" bajo una Sociedad de Responsabilidad Limitada (SRL); los Rougés, que explotaron el ingenio "Santa Rosa" en sociedad Colectiva hasta mediados de los '40; Los Frías y "Gallo y Peña", que a través de sociedades en comandita y colectivas, explotaron sus ingenios hasta la década de 1930. 
dose en una organización flexible, permeable y poco formal de colaboradores. Por otro lado, está la conducción que se orienta a gestionar los factores productivos, la cual se recuesta en una organización rígida, formal, con delegación de autoridades y relaciones impersonales (STEVENSON, 1989).

El primer tipo de dirección suele utilizarse generalmente en las empresas familiares, en tanto la "cabeza de grupo" oficia como núcleo centralizador de todas las decisiones. Por otra parte, su función no sólo está orientada al proceso productivo, sino que su capital relacional es de especial relevancia para la firma en facetas diversas como información, acceso al crédito, relación con proveedores, mercados, autoridades, etc.

En lo que respecta a la agroindustria tucumana, la participación de las sociedades familiares azucareras, aunque variable en el tiempo, siempre ocupó un lugar destacado. En muchos casos, la dirección personalizada de los negocios e incluso de la fábrica estuvo comandada por los empresarios primigenios y luego por sus sucesores. De este modo, en la manufactura cañera convivieron empresas con dirección gerencial profesionalizada (en su mayoría empresas de capitales extrarregionales), con empresas de dirección personalizada (característica general de las empresas de familia).

En el caso específico de A\&T, durante toda su historia los negocios fueron llevados de manera centralizada. Brígido Terán estuvo desde el principio al frente de los trabajos en la fábrica y plantaciones de caña. Luego de la muerte de Eudoro (padre), sumó a sus actividades la dirección de los negocios en la casa central. De este modo, se desempeñó por un largo período de tiempo como Administrador de la firma hasta poco antes de su muerte. Eudoro Avellaneda (h), como vimos, desde temprano desempeñó cargos directivos, actuando como mano derecha de su tío Brígido. Posteriormente, se desempeñó como Presidente de la firma, y aunque estaba asesorado por un Consejo de Administración, la última palabra le correspondía a su persona.

De este modo, A\&T conservaba muchos rasgos de una empresa de dirección personal, en tanto la coordinación última de todas las actividades residía en la figura del Socio-Administrador. Lamentablemente, no quedó asentado algún tipo de esquema organizacional de la firma, aunque a través de la información disponible en sus libros contables y en las Asambleas de Accionistas, podemos ensayar alguna aproximación a su estructura. Indagar sobre el tipo de organización de la dirección 
desarrollada por A\&T, puede resultar una forma válida de aproximación a las características de la dirección empresarial de las firmas azucareras familiares en la agroindustria tucumana.

Los destinos de la empresa estaban conducidos por un grupo de directivos unido por fuertes vínculos personales. La coordinación se obtenía principalmente por supervisión directa, estando el control de todas las operaciones en manos del Presidente (el Administrador de la sociedad). Lógicamente, la dirección y los pormenores de los trabajos en fábrica y cultivos estaba dirigida por personal ajenos a la familia, pero con una estrecha vinculación con los propietarios basada en años de trabajo y en lazos de confianza y amistad. Esto se puede comprobar por el hecho de que empleados superiores, en algunos casos, acudían a las Asambleas como representantes, no sólo de algún accionista, sino de Directores e incluso del Presidente. Esto sumado a una serie de gratificaciones por buen desempeño del personal, ayuda económica por bodas o auxilio por enfermedad del cónyuge, hace suponer que la relación entre empleados superiores y Directorio era de carácter personal ${ }^{39}$.

Si bien la estructura fue adquiriendo nuevos cuadros con la incorporación de la figura de un síndico procurador y la tercerización de los servicios de contabilidad mediante la contratación de "Price, Waterhouse, Peat y Cía" (mejorando notoriamente el asiento de datos y el control de la empresa), desde el punto de vista organizativo esta firma se caracterizó por una mixtura de elementos modernos con otros de antigua raigambre. Siguiendo la clasificación de Alfred Chandler, podríamos ubicarla como una unidad con estructura piramidal de subdivisión simple y dirección centralizada ${ }^{40}$, atravesada además por relaciones informales entre los directivos y el personal jerárquico (incluso entre el mismo Directorio), elementos no comprendidos en la clasificación anterior.

Esta estructura de gobierno parece haber sido la común entre, por lo menos, las empresas medianas del sector con control familiar. En este sentido, contamos con datos que acreditan una fuerte vinculación

39 La información citada se extrajo de los Libros de Asambleas de Accionistas. Archivo A\&T (1908-1949).

40 De acuerdo a la propuesta de Chandler sobre las formas básicas de organización de la empresa moderna, correspondería al tipo empleado por las empresas industriales de tecnología compleja luego de 1890 (CHANDLER, 1982:149). 
entre los directivos y personal superior en las empresas azucareras de los Frías (ing. San José), Terán (ing. Santa Bárbara), Griet (ing. Amalia), Simón Padrós (ing. Aguilares), García Fernández (ing. Bella Vista), Paz y Posse (ing. San Juan), Padilla (ing. Mercedes), Hill (ing. El Manantial), entre otros.

Esta característica de la gestión no debe llevar a suponer (como se ha sugerido frecuentemente) que la falta de una gerencia profesionalizada representa un indicador del retraso e incapacidad de conducción. Este esquema de organización pareció reflejar una alta flexibilidad en el funcionamiento de las firmas azucareras tucumanas puesto que, hasta la década de 1930, los ingenios que operaban bajo la gestión de firmas con propiedad y control familiar participaban alrededor del 45\% de la producción azucarera de la provincia ${ }^{41}$.

Esta permanencia y adaptabilidad en momentos de crisis contribuye a reforzar, por lo menos desde esta perspectiva regional, los postulados que relativizan la concepción "canónica” sobre la firma familiar como efimera e ineficiente. En efecto, autores como Colli y Rose han demostrado cómo la familia proveyó, tanto en el caso italiano como en el inglés, el marco organizacional idóneo para la industrialización temprana, manteniéndose, incluso, en economías maduras. (Colli y Rose, 2003). Por su parte, Valdaliso y López, criticaron la proposición de la única vía en la estrategia organizativa de las firmas, al sostener que:

[...] las empresas familiares no muestran una estructura o unos resultados sustancialmente diferentes a los de otras empresas. En otras palabras, es el tamaño y la complejidad de las actividades [...] lo que determina su estructura organizativa. En cuanto a la rentabilidad, no se puede afirmar de modo concluyente que las empresas familiares fueran más o menos rentables que las no familiares (VALDALISO y LÓPEZ GARCÍA, 2000:386-387).

Como esto sucede en otras partes del mundo, sobre todo en las sociedades de industrialización tardía, los estudios más actualizados del comportamiento empresarial se resisten cada vez más a calificar de tradicional a ese tipo de organizaciones, sobre todo si esta adjetivación

41 Este cálculo se realizó sobre la base de las cifras de producción consignadas en los Anuarios Estadísticos de la Provincia de Tucumán (varios años). 
peyorativa lleva a considerarlas menos eficaces que las de conducción exclusivamente profesional (CERUTTI, 2000:242).

\section{El desenvolvimiento económico de la empresa}

Lógicamente, un análisis de los resultados económicos alcanzados por las diferentes empresas de propiedad y control familiar permitirían evaluar la eficiencia de la dirección personal en este tipo de empresas azucareras y poner a prueba estas proposiciones. Empero, por motivos de espacio, esta tarea la reservamos para un futuro estudio centrado específicamente en las estrategias de desarrollo y resultados realizados por un segmento significativo de empresas familiares azucareras. Por lo pronto, nos conformamos con realizar una sucinta aproximación al desenvolvimiento experimentado por A\&T en los años bajo estudio.

¿Qué posibilidades de éxito tenía una empresa de mediana escala productiva para desenvolverse en el aleatorio mercado azucarero argentino? ¿Que tipo de estrategias implementó el Directorio de esta firma para mantener una performance aceptable hasta mediados de siglo?

Durante la etapa como sociedad colectiva (1879-1907), “Avellaneda \& Terán" evidenció una estrategia combinada de autofinanciamiento con una cautelosa política de inversiones. De este modo, se mantuvo una moderada capacidad productiva de la fábrica, atento a las posibilidades de absorción del mercado interno, y se complementó el negocio azucarero con el sector inmobiliario urbano y rural, con el objetivo de asegurar la solidez patrimonial y amortiguar, en años difíciles, los reveses de la actividad azucarera (CAMPI, 2006: 229-272).

Luego de su reconversión en "comandita por acciones" se mantuvieron, en líneas generales, el nivel de las operaciones, combinado con una prudente política de endeudamiento. Sin embargo, algo cambió. Por una parte, se produjo el reparto de los bienes inmuebles urbanos entre los socios de la firma anterior, iniciándose la nueva razón social con las seis propiedades rurales adquiridas en el período previo, además del ingenio. Por otra parte, los integrantes del Directorio se asociaron, como ya se indicó, con personalidades del espectro político y empresarial de la provincia para explotar el ingenio Santa Lucía, que fue reacondicionado y puesto en un nivel productivo similar a Los Ralos. A esto se sumó la 
participación de Brígido como accionista en el ingenio Las Palmas (ubicado en el Territorio Nacional del Chaco) a partir de 1909, y el arriendo del ingenio El Manantial, en sociedad con su yerno Percy Hill, desde la zafra de 1912 hasta $1916^{42}$.

De este modo, el perfil azucarero que mostró la familia desde sus inicios, fue acentuado luego de la reconversión a Comandita. Este fue el movimiento inicial de una política expansiva que se mantuvo con oscilaciones hasta la década de 1930, consistente en la modernización de la fábrica y la integración vertical del establecimiento, mediante la compra y cultivo de amplias extensiones de cañaverales propios. Asimismo, la apuesta fuerte en el negocio azucarero nos permite evaluar el nivel de confianza y buenas perspectivas que ofrecía la actividad, a pesar del temor recurrente de la sobreproducción y de los vaivenes climatológicos que incidían directamente en los resultados de las zafras.

Cuadro № 2 - Comparación de los ingenios ‘Los Ralos’ y ‘Santa Lucía’ según producción media anual de azúcar

\begin{tabular}{l|c|c|c|c|c|c|c|c|c}
\hline \multicolumn{1}{c|}{ Ingenios } & \multicolumn{3}{|c|}{$\begin{array}{c}\text { Período } \\
(1895-1916)\end{array}$} & \multicolumn{3}{c|}{$\begin{array}{c}\text { Período } \\
(1917-1930)\end{array}$} & \multicolumn{3}{c}{$\begin{array}{c}\text { Período } \\
(1931-1949)\end{array}$} \\
\hline & (a) & (b) & (c) & (a) & (b) & (c) & (a) & (b) & (c) \\
\hline Los Ralos & 12 & 8,1 & 3.662 & 14 & 7,5 & 7.203 & 9 & 8,3 & 9.835 \\
\hline Santa Lucía & 23 & 7,8 & 2.069 & 12 & 7,4 & 7.803 & 10 & 8,2 & 9.703 \\
\hline Media general & 28 & 7,6 & 4.327 & 26 & 7,2 & 8.528 & 28 & 8,2 & 9.864 \\
\hline
\end{tabular}

Fuente: elaboración propia a partir del Anuario Estadístico de la Provincia de Tucumán, 1895-1949 y de La Revista Azucarera - La Industria Azucarera, 1894-1949.

Nota: (a) ubicación de acuerdo su participación en el total de la producción tucumana; (b) rendimiento industrial (porcentaje de azúcar sobre caña molida); (c) Producción en tn.Varios ingenios que fueron excluidos del cálculo por no haber molido más de la mitad de los años analizados por período, por lo que no los consideramos determinantes en el resultado general.

Tras el período de subproducción, que se extendió entre 1906 y 1912, le siguieron dos años de excelentes zafras que preocuparon a los industriales por el temor de abarrotar el mercado. De todos modos, estos temores se transformaron inmediatamente en pánico, pero por causas diferentes. Entre 1915-1917 la denominada "plaga del mosaico" atacó los cañaverales tucumanos, reduciendo la producción en altísimos

42 Monitor de Sociedades Anónimas, Tomo VIII, 1909. p.127; APJT, RPC, CM, "Hill y Terán”, Tomo IX, 1911. fs. 315-316. 
niveles y poniendo en serio riesgo la continuidad de la actividad. Esta crisis fue superada por el replante extensivo de variedades de cañas importadas de Java y aclimatadas en la Estación Experimental, resistentes a la plaga y con mayores rindes culturales y sacarinos.

Pero la difusión de estas nuevas gramíneas trajo como consecuencia un aumento significativo de la producción, iniciándose en 1925 un nuevo período de sobreoferta de azúcar en un mercado interno con menor tasa de crecimiento que en años anteriores debido al corte del aporte inmigratorio. Esto, lógicamente, provocó una situación de inestabilidad de los precios con una tendencia a la baja, influenciada además por la situación del mercado mundial, que luego de la recuperación de la producción de los azúcares de remolacha, se incrementó la competencia entre los principales centros productores por sus porciones en el mercado, generando un nuevo período de sobreoferta internacional. El impacto de esta situación incidía desfavorablemente en la Argentina por la incapacidad de exportar sin pérdidas debido a los costos productivos comparativamente superiores, sumado a las políticas de dumping aplicadas por los estados exportadores de azúcar (SANTAMARÍA, 1986:36).

De este modo, luego de tres años consecutivos de sobreproducción, el conflicto entre industriales y cañeros independientes (componente determinante dentro del complejo agroindustrial tucumano) por las cuotas de molienda, el precio de la materia prima y la distribución del ingreso azucarero, llegó a su cenit con la masiva huelga cañera de 1927 y la completa paralización de la zafra, cuyo capítulo final fue el Laudo Arbitral del Presidente de la Nación ${ }^{43}$.

43 El Laudo Presidencial de 1928 estableció finalmente un sistema de coparticipación en la agroindustria. Esto constituyó el más serio intento promovido hasta entonces para proteger a los plantadores (en su gran mayoría pequeños y medianos propietarios) ante los industriales. En efecto, con un mecanismo de control y regulación de los precios de la caña, se pretendía garantizar que a los cañeros se les abonara un equivalente del $50 \%$ de los azúcares fabricados, pues se entendía que el costo de producir una tonelada de caña era equivalente a una tonelada de azúcar. De este modo se instaló la concepción de la "protección distributiva" que tenía como base la idea que una industria merecía el resguardo del Estado, siempre que propicie el bienestar de la sociedad y no solamente el de un sector. Por otra parte, se aseguró a los plantadores la molienda de su producción por medio de la distribución de cupos a cañeros que deberían registrarse para obtener prioridad en la molienda, ingresando caña adicional cuando en un ingenio no se hubiese completado la cuota 
A inicios de la década de 1930 se dictaron diversos mecanismos de regulación de la producción a nivel provincial. Las directivas se aplicaron en un contexto extremadamente adverso a las empresas azucareras por la situación de sobreproducción, acumulación de stocks y bajos precios. Estas regulaciones limitaron las cosechas en cada ingenio y fijaron cuotas de venta para impedir que se volcara al mercado un volumen mayor al consumo nacional. Se consiguió otorgar cierto marco de estabilidad en la provincia para contrarrestar los efectos de la sobreproducción, pero al no existir una legislación reguladora nacional, las restantes zonas azucareras siguieron incrementando sus volúmenes, contrarrestando el esfuerzo para constreñir la oferta (BRAVO, 2004).

De todos modos, se alcanzó un equilibrio aceptable a mediados de la década de 1930, manteniéndose el régimen de regulaciones hasta los años '40.

Respecto a nuestro estudio de caso, la salud de las cuentas patrimoniales, sumado a una estrategia acertada de ventas durante el período de sobreoferta, habría permitido descomprimir sus depósitos de azucares, manteniendo unos márgenes de utilidades aceptables dentro de la situación del mercado.

Durante la década de 1930, los negocios de la empresa mantuvieron el rubro del azúcar como la principal fuente de ingresos. No obstante, a fines del periodo estudiado fueron cobrando importancia otras actividades, aunque no de modo determinante. En este sentido, se advierte un paulatino cambio de estrategia de la empresa, con la introducción de nuevos cultivos y una incipiente orientación hacia otras actividades.

de molienda. Además, el Laudo sentó las bases para la regulación de la producción, a través de un límite a la elaboración de cada ingenio, con el fin de no generar una sobreoferta de azúcar en un mercado limitado (CAMPI, 2000: 12; BRAVO, 2008 : 265-321). 


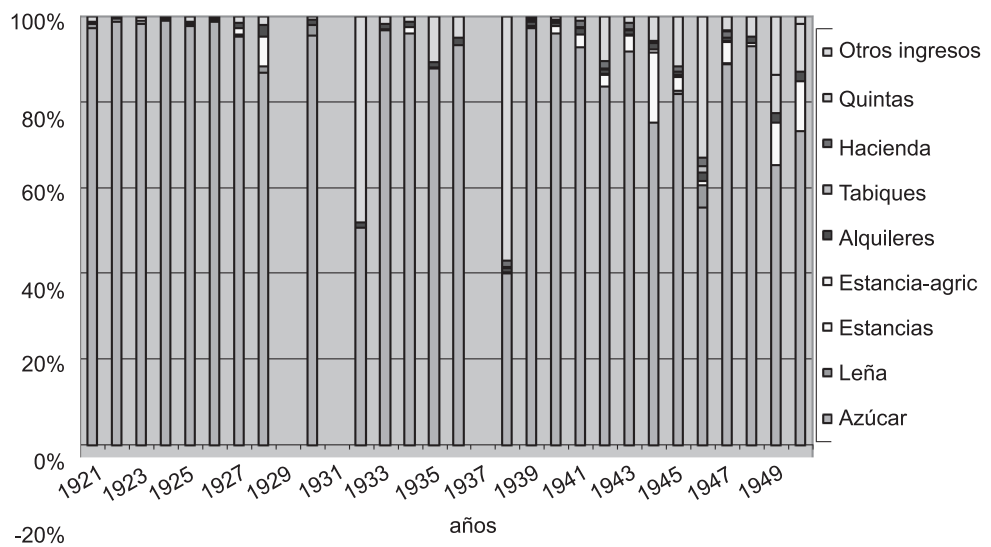

Fuente: Elaboración propia a partir del Libro de Asambleas de Accionistas y de los Estados de Pérdidas y Ganancias (varios años). Archivo A\&T.

Nota: Hemos agrupado en rubro "Azúcar" todos los ingresos que procedían de ventas de azúcares, alcohol y melaza. Durante los años 1933 y 1939, las diferentes las cuentas no se especificaron debidamente, por ese motivo figura una gran proporción de las entradas en el rubro "Otros Ingresos".

De este modo, se pusieron en marcha ensayos con variedades de algodón, maíz y girasol, aunque en proporciones reducidas y de modo discontinuo. A la par, cobró mayor fuerza la compra-venta de hacienda (repartida en mulares y vacunos), fluctuando alrededor de 2.000 cabezas anuales, cifra nada desdeñable para la producción pecuaria tucumana. Por otra parte, la cuenta "alquileres" (que seguramente se refería a arrendamientos de tierras) y "quintas" (citrus) mostraron, en diferentes períodos, un dinamismo apreciable. En definitiva, aunque es innegable que el rubro azúcar mantuvo una importancia central en los resultados de la empresa durante todo el período, la búsqueda de otros cultivos y actividades podría estar mostrando una estrategia de diversificación de activos para contrarrestar la paulatina pérdida de rentabilidad del negocio azucarero, como veremos más adelante.

De todas maneras, este panorama sólo es una reconstrucción sobre la base de las partidas de entradas de cada año, lo que nos muestra la composición porcentual de los ingresos, pero no su volumen. Por tal motivo, para formarnos una idea más acabada sobre la marcha de la empresa, será necesario centrarnos en el análisis de sus utilidades. 
La firma, una vez establecida con su nueva razón social, amplió su capital en dos oportunidades. En 1907, la comandita se conformó con $\$ 2.550 .000 \mathrm{~m} / \mathrm{n}$; en 1921 , esta suma ascendió a $\$ 5.100 .000 \mathrm{~m} / \mathrm{n}$, sin variar el número de acciones; y por último, en 1941, el capital social de la empresa se colocó en $\$ 7.650 .000 \mathrm{~m} / \mathrm{n}$. Ahora bien, la ampliación de capital social no buscaba la incorporación de dinero para expandir actividades o sanear sus pasivos, sino que respondió a la necesidad de actualizar los valores para colocar las operaciones en sintonía con la economía real. Si bien es cierto que en las dos oportunidades se incorporó el Fondo de Reserva a la cuenta Capital, éste no fue suficiente para cubrir el total de la ampliación, por lo que podríamos conjeturar que se trató de una puesta al día de los valores. Sin embargo, el mantener subvaluados los valores contables de algunas partidas del Activo, generó un flujo importante de Reservas “ocultas”, que al no ser declaradas, quedaron, de hecho, en manos de la empresa.

Cuadro № 3 - Ampliación de capital social en diferentes períodos (\$ a valores nominales)

\begin{tabular}{l|c|c|c}
\hline Avellaneda \& Terán & 1908 & \multicolumn{1}{c|}{1922} & \multicolumn{1}{c}{1941} \\
\hline Capital Social & 2.550 .000 & 2.550 .000 & 5.100 .000 \\
\hline Fondo de Reserva & & 357.400 & $137.641,70$ \\
\hline Aumento por nueva avaluación & & 2.192 .600 & $2.412 .358,30$ \\
\hline Total & 2.550 .000 & 5.100 .000 & 7.650 .000 \\
\hline
\end{tabular}

Fuente: Elaboración propia a partir de Actas de Asamblea de Accionistas (1908-1949). Archivo A\&T

Respecto a los dividendos, no poseemos un registro sistemático antes de 1921. Sin embargo, estamos en condiciones de afirmar que, con excepción de los años de crisis, rondaron el 10\% (a pesar que esa cifra puede resultar un tanto engañosa por permanecer los activos subvaluados). A partir de 1922 la contabilidad de la empresa se torna más detallada, permitiéndonos determinar la distribución de dividendos de alrededor del 8\% promedio entre 1922 y 1949 . Una característica de este reparto consistió, sobre todo durante en los años '30, en aplicar una política de sumas fijas para distribuirlas entre los accionistas, de modo tal que en años de grandes utilidades, estas sumas pasaban a enriquecer el Patrimonio de la empresa. 
A partir de 1922, de acuerdo a los Estatutos, el 2\% de las utilidades se destinaban al Fondo de Reserva. De todos modos, la empresa utilizó otros tipos de acumulación de utilidades, como las Reservas Extraordinarias, Reservas para amortización, Reservas para deudores incobrables y el pase de saldos sobrantes a cuenta nueva. Por contar solamente con los "Estados de Pérdidas y Ganancias", no podemos establecer el estado de cada cuenta en cada año, salvo cuando se especifica este pase de las utilidades no repartidas. Sin embrago, a través de la comparación entre los Dividendos y las Utilidades Netas, podemos formarnos una idea de la magnitud del respaldo de la firma.

Gráfico № 2 - Utilidades Netas y Dividendos, 1930-1949, en valores deflactados de acuerdo al índice de precios mayoristas (base: 1935)

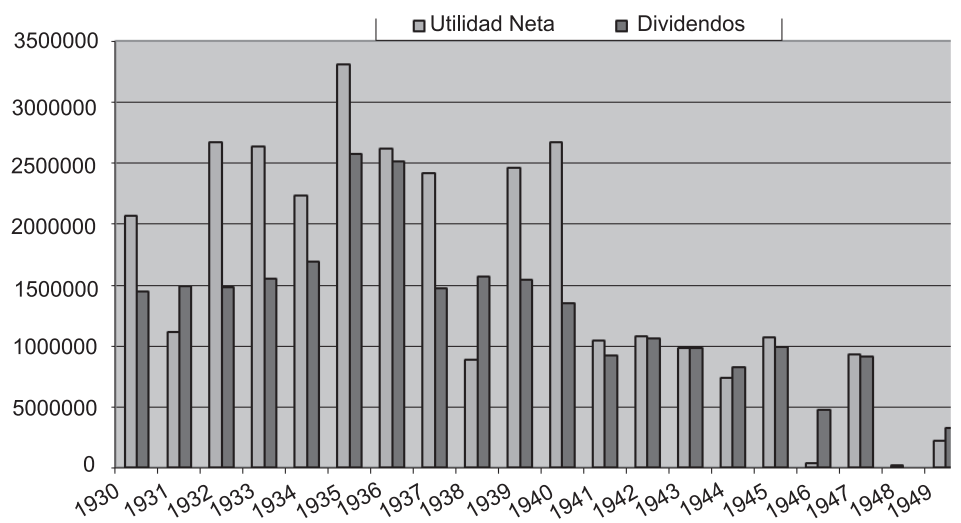

Fuente: Elaboración propia a partir de Actas de Asamblea de Accionistas (1930-1949).

Nota: La deflactación de los valores fue realizada a través de un cambio de base, utilizando un índice de precios mayoristas con base 1993. De este modo, nos permite valuar de un modo más aproximado las utilidades o los valores a pesos (\$) del año base elegido, que en este caso fue 1935. Los índices de precios mayorista figuran en (FERRERES, 2005:451).

De este modo, se trasluce el mantenimiento de una "tradición" de la firma de financiarse con recurso genuinos a través de la retención de utilidades. Además, resultó una práctica común el depósito de efectivo por parte de los socios a cambio de un interés similar al ofrecido en plaza. De este modo, se evitaba la extracción de utilidades no distribuidas y permitía a la firma disponer de capital sin necesidad de apelar a grandes préstamos bancarios. 
Sin embargo, no deja de llamar la atención que al alza de las utilidades descripta durante toda la década de 1930, le siga un descenso sostenido en los años '40, restringiéndose el nivel de ganancias a fines del periodo analizado. Esta situación podría tener diferentes causas: desde una perspectiva centrada en la firma, la reavaluación de los activos efectuada en 1941 habría producido el ajuste de los valores, expresando el monto de las utilidades en relación más cercana a la economía real. Por otro lado, esta actualización necesariamente debía conllevar una mayor carga impositiva, con la consiguiente erogación de efectivo. Paralelo a esto, una nueva calamidad en los cañaverales tucumanos, la plaga del "carbón" o "tizón", afectó fuertemente a la producción entre las zafras1940-1943, incidiendo notablemente en la empresa, ya que la mayor parte de la molienda se realizaba con caña propia. Esto habría obligado a comprar caña de terceros, con el consiguiente aumento de costos.

Por otra parte, las políticas con fuerte contenido social implementadas desde 1943 y acentuadas durante los gobiernos peronistas (19461955), modificaron las pautas de negociación y distribución de la renta azucarera.A partir de entonces, los trabajadores sindicalizados ingresaron como un actor de peso en el prorrateo de los beneficios generados por la actividad. Asimismo, se continuó con el régimen de regulaciones, aunque en este período se establecieron disposiciones que tuvieron alcance nacional (BRAVO-GUTIÉRREZ, 2009). Empero, no contamos aún con investigaciones que contemplen de manera íntegra la situación de la actividad desde la faz productiva, y menos aun en lo referente a las políticas azucareras llevadas a cabo en la década de 1940 y durante el peronismo. Si bien existen aproximaciones al respecto, no poseemos una masa crítica de estudios que permitan evaluar la situación de la actividad azucarera en su conjunto.

En este contexto el Directorio de "Avellaneda \& Terán” liquidó la sociedad en comandita, conformando en 1949 una nueva firma, esta vez, como Sociedad Anónima. ¿Qué elementos habrían determinado el cambio de la razón social? A primera vista, se podría argumentar que el constante descenso de las utilidades habría motivado esta transformación (en 1946 y 1948 las ganancias fueron casi nulas). Empero, existen otros elementos que no permiten tomar esta razón como exclusiva. A\&T entre 1948 y 1950 poseía un Activo de $\$ 7.726 .325 \mathrm{~m} / \mathrm{n}$ y un Pasivo de $\$ 3.886 .655 \mathrm{~m} / \mathrm{n}$, por lo tanto, se debería descartar una situación suma- 
mente comprometida en las finanzas, por lo menos hasta finales de esta década. ${ }^{44}$ Esta circunstancia tiene un valor adicional si consideramos que varias firmas azucareras, desde "medianas" hasta "grandes" empresas, se encontraban entonces fuertemente endeudadas.

Por otra parte, el desempeño del ingenio en su conjunto no parece indicar un descenso de la productividad. Un estudio interno realizado por el Banco Central de la República Argentina, ubicó a Los Ralos dentro de los ingenios "tipo" o "económicos", entendiendo esta categoría como "aquel que responde a la definición dada para la unidad económica de producción agrícola: de volumen suficiente para sostener la economía de la empresa que lo explota en forma racional, sin lesionar la economía colectiva" (BCRP,1949:13). Es interesante destacar que en esta categoría quedaron calificados 14 ingenios tucumanos, cuatro en una categoría intermedia y 11 unidades fabriles tucumanas consideradas como "antieconómicas". Creemos que esto representa un claro indicio sobre la existencia de problemas estructurales en el sector, corroborando, de algún modo, la pérdida de dinamismo y rentabilidad de la actividad azucarera. Sin embargo, también este estudio nos permite observar que de los ingenios estudiados 10 unidades de alta y mediana eficiencia pertenecían a sociedades de propiedad y control familiar, mientras que solo cuatro ingenios de estas características le correspondieron la categorización más baja (BCRA, 1949: 15). Por lo tanto, nuevamente estamos ante evidencia que obliga a reconsiderar las empresas familiares o de gestión "no profesionalizada" como irremediablemente conservadoras e ineficientes.

Pero volviendo a nuestro interrogante inicial, el hecho de mantenerse el ingenio en buen funcionamiento, junto con los pasivos controlados y un buen nivel productivo, permite suponer que jugaron otras variables en la reconversión de A\&T en Sociedad Anónima. En este sentido, creemos que desde una perspectiva interna de la firma podemos encontrar algún tipo de explicación.

A finales del período bajo estudio, los socios primigenios Brígido Terán, Julio J. Cainzo, Ezequiel Gallo y Evaristo Etchecopar habían fallecido. A su muerte, los herederos recibieron en partes proporcionales las acciones, manteniéndose la participación de la mayoría de sus sucesores en la firma. Si bien Eudoro Avellaneda (h) se mantuvo como

44 Los datos se extrajeron de (GIRBAL-BLACHA. 2003:155-156). 
Administrador durante estos años, es posible que el recambio generacional del Directorio, sumado a la alta dispersión de las acciones, hayan contribuido, de algún modo, a minar el consenso sobre la dirección de los negocios. Sumado a esto, y aunque resulte reiterativo, la creciente incertidumbre de la actividad pudo haber inducido a los socios a limitar la responsabilidad social ${ }^{45}$.

Por otra parte, la formación en S.A. puede haber servido para consolidar el paulatino proceso de diversificación iniciado en los años ‘30, al integrar en una misma empresa actividades que desde hacía tiempo venían realizando los mismos miembros de A\&T, pero bajo razones sociales paralelas, como ser la cría y comercialización de ganado, la compra venta de inmuebles o la explotación de quintas (citrus) en gran escala. Además, no es un dato menor que socios destacados de la firma, como Juan Manuel Terán Vega o Eudoro Avellaneda (h) se desempeñaran desde tiempo atrás en el ámbito de las finanzas y los seguros.

En definitiva, en 1949 la Asamblea de accionistas se pronunció favorablemente a la reconversión en S.A., incluido el propio Presidente Eudoro Avellaneda. En este sentido, el paso de A\&T a "Sociedad Anónima Industrial, Comercial, Agrícola, Ganadera, Inmobiliaria y Financiera”, más que a una alternativa última por subsistir en el negocio del azúcar, pareció obedecer a una estrategia combinada de ampliación e integración de actividades en una misma firma, junto a la búsqueda del resguardo patrimonial a través de la limitación de la responsabilidad social. A partir de entonces, Eudoro Avellaneda se desempeñó al frente de los directorios de A\&T y “Cía. Azucarera Santa Lucía”, hasta inicios de la década de 1960.

\section{Conclusiones}

La principal razón que impulsó este estudio fue la necesidad de problematizar el análisis de la agroindustria tucumana a partir del análisis de algunas empresas del sector. En este caso, se persiguió dar cuen-

45 Además de la inestabilidad del mercado, es necesario indicar la desconfianza que significó para los sectores dominantes tradicionales el arribo del peronismo al gobierno nacional y provincial. 
ta de las diferentes alternativas a las que se enfrentaron los directivos de $\mathrm{A} \& \mathrm{~T}$ en lo referente a los vaivenes del mercado, la relación empresa/ familia y las estrategias empresariales de reproducción patrimonial, buscando eludir, de este modo, las visiones forzadamente homogéneas sobre los empresarios y las empresas azucareras de este complejo agroindustrial, y de las posturas que conciben una superioridad intrínseca de las modernas empresas gerenciadas por sobre las gestionadas por la familia.

De este modo, a través de estas páginas hemos transitado algunos aspectos de la historia de una empresa azucarera del norte argentino, de la cual se pueden extraer algunas reflexiones.

Por una parte, pudimos ver cómo luego de la salida de la crisis de 1895-96 se inauguró entre las empresas controladas por familias tucumanas una tendencia a reconvertirse en Sociedades Anónimas. En efecto, si en un principio prevaleció la asociación solidaria o la propiedad individual, la opción por la S.A. en el parque azucarero tucumano comenzó a tener aceptación. Este tipo societario ofrecía ventajas en tanto limitaban las responsabilidades a la vez que significaba una vía interesante de capitalización sin endeudamiento. Empero, en el caso de las firmas familiares tucumanas pudimos comprobar que se trató de una estrategia para incorporar parientes, limitar la responsabilidad y preservar el patrimonio de la familia antes que la búsqueda de inversores foráneos para la expansión de las operaciones.

Además, quedó comprobado el peso cualitativo que tuvieron las redes parentales y amicales en la firma bajo estudio, influencia que podría hacerse extensiva a las firmas de propiedad y control familiar dentro de la actividad. Estas redes sociales no sólo aportaron la base de unión y confianza necesarias para la formación de emprendimientos comunes en diferentes rubros de la economía. También fueron el canal por donde se transmitieron información y se reforzaron los vínculos de reciprocidad, como también los valores y las aptitudes empresariales.

En estrecha relación con lo anterior, durante los años ' 20 se produjo un generalizado recambio de los planteles empresariales, con el apartamiento o deceso de los socios fundadores y la asunción del control de las firmas por parte de sus descendientes. De este modo la cuestión de la sucesión generacional en los puestos dirigenciales fue un tema que despertó nuestro interés identificando una serie de estrategias en $A \& T$ que permitieron 
sortear este escollo y otorgarle un margen de estabilidad y un plan de acción a la empresa, que indudablemente incidieron de manera favorable en la marcha de los negocios.

Por otro lado, podemos destacar el derrotero satisfactorio que desarrolló esta firma, manteniendo la propiedad y el control dentro de la familia, a través de una forma mixta de asociación y de una estructura simple de gestión. Esta empresa apostó a una estrategia que combinó el endeudamiento con la autofinanciación, unido a una política sostenida de inversiones e integración productiva que le permitió reducir costos y poseer el respaldo necesario para reaccionar adaptativamente a las señales del contexto. Incluso, cuando el rubro azucarero mostró una paulatina baja de la rentabilidad, la firma inició la búsqueda actividades alternativas como una vía para diversificar los activos y mantener el nivel de ingresos.

A pesar de las dificultades evidenciadas por el mercado, al analizar la composición empresarial del complejo tucumano a finales de los años '30, notamos una fuerte pervivencia del elemento familiar en las empresas. Es evidente que la fuerte presión en los pasivos de algunas firmas y la sucesión de malos resultados motivaron la quiebra o el ingreso de nuevos actores, los que en calidad de acreedores mayoritarios pasaron a controlar los destinos de algunas de ellas. De todos modos, no se evidenció una pérdida de la primacía del elemento familiar en gran parte de las empresas, manteniéndose alrededor del $45 \%$ de la producción total en los últimos años bajo estudio.

En definitiva, los negocios de esta burguesía regional, aunque exhibieron una amplia movilidad entre diversos sectores de la economía, evidenciaron un marcado perfil azucarero y se realizaron básicamente a través de sociedades familiares. La unidad empresarial predominante, más allá de su estructura jurídica, por lo menos hasta finales de los años '30, fue la empresa familiar comandada por la 'cabeza' del grupo, o bien, por la gestión de los descendientes del 'fundador'. Esta continuidad de los negocios familiares venía a depender, en gran medida, de la presencia de capacidades empresariales en los descendientes, desarrolladas a través de un entrenamiento tácito y de la utilización de activos inmateriales que heredaron de sus progenitores. De este modo, al igual que otras burguesías regionales (como el norte de México, el País Vasco e inclusive el Norte de Italia, entre otras), diversas familias azucareras lo- 
graron formar desde una matriz 'tradicional', una serie de cuadros empresariales que evidenciaron una buena performance al frente de sus empresas (CERUTTI, 2000; COLLI, FERNÁNDEZ PÉREZ, ROSE, 2003; CERUTTI y VALDALISO, 2003).

Por el momento, no podemos definir un patrón único sobre el carácter familiar cerrado de algunas familias empresarias. Mientras unas se abrieron y asociaron con otros capitalistas desde finales del siglo XIX, otras se mantuvieron como empresas familiares conectadas sólidamente por vínculos parentales y amicales. En ellos la familia fortaleció su función de soporte inmaterial y cultural para articular y armonizar intereses económicos, a la vez que desarrolló un entramado de solidaridades y conocimientos que permitieron operar como una vía de transferencia de know how, información, contactos y solidaridades. En modo alguno esto significó un obstáculo para el desarrollo y la modernización de la agroindustria, como se desprende de los resultados de este estudio.

Como en toda aproximación, sus conclusiones podrán enriquecerse o refutarse cuando se cuente con estudios sobre un número más amplio de empresas azucareras, ya sean tucumanas o de otras provincias argentinas (o por qué no latinoamericanas). Confiamos en que ello será posible a corto plazo.

\section{Bibliografía}

Álbum Argentino. Provincia de Tucumán: su vida. Su trabajo. Su progreso. Buenos Aires, 1910

BARBERO M. y Rocchi, F. Cultura, sociedad, economía y nuevos sujetos de la historia: empresas y consumidores, en Bragoni, Beatriz (edit). Microanálisis. Ensayos de historiografía argentina. Buenos Aires: Prometeo, 2004.

BARBERO, M. La historias de empresas en Argentina: trayectorias y temas en debate en las últimas dos décadas. en Gelman, Jorge (comp.). La historia económica argentina en la encrucijada. Balances y perspectivas. Buenos Aires: Ptometeo Libros, 2006.

BJERG, María \& BOIXADÓS, Roxana (eds.). La familia. Campo de investigación interdisciplinario. Teorías, métodos y fuentes. Buenos Aires: Universidad Nacional de Quilmes, 2004.

BOZZO, Rubén. La problemática de las empresas de familia. Realidad Económica, № 167 , Buenos Aires, 1999. 
BRAVO, M. Crisis y regulaciones azucareras, 1928-1938. Actas de las XIX Jornadas de Historia Económica, Asociación Argentina de Historia Económica- Universidad del Comahue, Argentina, 2004.

.Las leyes 'machete' y la ruptura del frente azucarero. en Campi, Daniel (Comp). Estudios sobre la Historia de la Industria Azucarera Argentina, Tomo I, Facultad de Ciencias Económicas, UNT- Unidad de Investigación Regional, UNJu, 1993: $97-$ 138.

. Campesinos, azúcar y política: cañeros, acción corporativa y vida política en Tucumán (1895-1930). Rosario: Prohistoria Ediciones, 2008.

CAMPI, Daniel (a). Modernización, auge y crisis. el desarrollo azucarero tucumano entre 1876 y 1896. En VIERA, Alberto et al: História e tecnología do açucar. Funchal (Madeira): Centro de Estudios de História do Atlântico, 2000.

(b). Política azucarera argentina 1945-1990. Regulación y crisis, 2000 (Inédito).

Azúcar y Trabajo. Coacción y mercado laboral en Tucumán, Argentina. 1856-1896. Tesis Doctoral defendida en la Universidad Complutense de Madrid, 2002 (inédita).

Avellaneda \& Terán, una empresa azucarera argentina en tiempos de crisis (1892-1906), en Cerutti, M. (coord.). Empresas y grupos empresariales en América Latina, España y Portugal. Monterrey: Universidad Autónoma de Nueva León, 2006.

CAMPI, Daniel. y JUÁREZ Dappe, Patricia. Argentina y Perú: semejanzas y contrastes de modelos azucareros, 1880-1930, Illes i Imperis 9, Barcelona: Universidad Pompeu FRABRA, 2006

y BRAVO, María Celia. Azúcar, Empresarios y Estado-Nación en el Noroeste Argentino (1880-1930). Comunicación presentada en el $49^{\circ}$ Congreso Internacional de Americanistas. Pontificia Universidad Católica del Ecuador, 1997.

La agroindustria azucarera argentina. Resumen historiográfico y fuentes. América latina en la historia económica. Boletín de fuentes 11. 1999: 73-93.

CERUTTI, Mario. Propietarios, empresarios y empresa en el norte de México. México: Siglo XXI, 2000.

y Valdaliso. Monterrey y Bilbao (1870-1914). Empresariado, industria y desarrollo regional en la periferia. Historia Mexicana, abril-junio,Vol. LII, N 4, México, 2003.

CHANDLER, Alfred D. (Jr.). La mano visible. La revolución en la dirección de la empresa norteamericana. Madrid: Ministerio de Trabajo y Seguridad, 1987.

. Scale and Scope. The Dynamics of industrial Capitalism. Harvard University Pres, 1990.

COLLI, A. y ROSE, M. Family firms in comparative perspective. Amatori, F. and Jones, G. (eds.). Business History around the World at the End of the Century. Cambridge Univertity Press, 2003.

COLLI,A.; FERNÁNDEZ PÉREZ, P.y ROSE, Mary. National Determinants of Family Firm Development? Family Firms in Britain, Spain, and Italy in the Nineteenth and Twentieth Centuries. Enterprise \& Society, Vol 4, N 1, Oxford, 2003: 23-64. 
CHANDLER, Alfred. Los Estados Unidos. La evolución de la empresa, en P. Mathias y M. Postan (eds.). Historia Económica de Europa. Tomo VII. Madrid: Ed. Revista de Derecho Privado, 1982.

FERNÁNDEZ PÉREZ, Paloma. Reinstalando la empresa familiar en la Economía y la Historia económica. Una aproximación a debates teóricos recientes. Cuadernos de Economía y Dirección de la empresa 17, España: 2003.

FERRERES, Orlando (dir.). Dos siglos de economía argentina (1810-2004). Buenos Aires: Fundación Norte Sur, 2005.

GALlO,Vicente. Crisis Azucarera. Anales de la Facultad de Derecho y Ciencias Sociales, $\mathrm{N}^{\circ}$ 1, Buenos Aires, 1902.

GARCÍA LÓPEZ, José. Las sociedades colectivas y comanditarias en la dinámica empresarial española del siglo XIX. Revista de Historia Económica, Vol. XII, N ${ }^{\circ}$, 1994.

GERSICK, K. et al. Generation to Generation: Life Cycles of the family business. Boston (Massachussets): Harvard Business School Press, 1997.

GIRBAL-BLACHA, Noemí: Mitos, paradojas y realidades en la Argentina peronista (19461955). Bernal: Universidad Nacional de Quilmes, 2003.

GUY,Donna. Política azucarera argentina:Tucumán y la generación del 80.Tucumán: Ediciones Fundación Banco Comercial del Norte, 1981.

La industria argentina, 1870-1940. Legislación comercial, mercado de acciones y capitalización extranjera. Desarrollo Económico 87, Octubre-Diciembre. Buenos Aires: 1982.

HERRERA, Claudia. Élites y poder en Argentina y España en la segunda mitad del siglo XIX. Tesis Doctoral defendida en la Universidad complutense de Madrid: Madrid, 2003.

. Patrimonio, sucesiones y alianzas matrimoniales en la élite tucumana. Actas de las Primeras Jornadas Nacionales de Historia Social, La Falda (Córdoba), 2007.

JAMES, Harold:Family Capitalism:Wendels, Haniels, Falcks, and the Continental European Model. Harvard University Press/Belknap, Cambridge, MA, 2006.

Ledesma SAAIC. Ledesma. Historia de una empresa Centenaria: Buenos Aires, 2008.

LENIS, María. Estrategias corporativas y discurso empresario: El Centro Azucarero Argentino, 1894-1923.Tesis doctoral defendida en la Facultad de Filosofia y Letras, UNT, 2009 (inédita).

LEWIS, Paul. La crisis del capitalismo argentino. Buenos Aires: Fondo de Cultura Económica, 1993.

LÓPEZ, Andrés. Empresarios, instituciones y desarrollo económico: el caso argentino. Buenos Aires: CEPAL, 2006.

MARTÍNEZ, Alberto. Consideraciones sobre el censo de los valores inmobiliarios en III Censo Nacional de la República Argentina, Tomo X. Buenos Aires:Talleres Gráficos Rosso y Cia., 1919.

MERCADO, Lucía. El ingenio Santa Lucía de Tucumán, los primeros habitantes, $2^{a}$ ed. Buenos Aires: el autor, 2003. 
MORENO FRAGINALS, Manuel. El ingenio. Complejo económico social cubano del azúcar. La Habana: Editorial de Ciencias Sociales, 1986.

MOYANO, CAMPI y LENIS. La Estación Experimental Agrícola de Tucumán en tiempos dificiles, 1909-1920. Actas del Primer Congreso Latinoamericano de Historia Económica - 4 Jornadas Uruguayas de Historia Económica, Montevideo:AAHE,ABPHE, ACHE, AMHE, AUDHE, 2007.

NELSON, R. y WINTER, S. Uma teoria evolucionária da mudança econômica (1º ed. 1982). Campinas: Editora Unicamp, 2005.

NOUGUÉS, Miguel Alfredo: Los fundadores, los propulsores, los realizadores de San Pablo. Tucumán: Ed. del autor, 1976.

PADILLA,Vicente: El Norte Argentino. Buenos Aires: Establecimientos Ferrari Hnos., 1922.

PENROSE, Edith. A Teoria do crescimento da firma. Campinas SP: Editora UNICAMP, 2006. $\left(1^{\circ} \mathrm{Ed} .1959\right)$.

REgUERA, Andrea. Patrón de Estancias. Ramón Santamarina: una biografía de fortuna y poder en la pampa. Buenos Aires: Eudeba, 2006.

ROSE, Mary. Beyond Buddenbrooks: the family firm and the management of secession in nineteenth-century Britain. en Brown, Jonathan and Rose, Mary (eds). Entrepreneurship, Networks and Modern Business: Manchester University Press, 1993.

ROSENBLATT, P. C. et al. The Family in Business. San Francisco (California): Jossey Bass Publishers, 1990.

SÁNCHEZ ROMÁN, J. (a) La Dulce Crisis. Estado, Empresarios e Industria Azucarera en Tucumán, Argentina (1853-1914). Diputación de Sevilla: Universidad de Sevilla, Consejo Superior de Investigaciones científicas, Escuela de Estudios HispanoAmericanos, 2005.

. (b) La industria azucarera en argentina (1860-1914). El mercado interno en una economía exportadora. Revista de indias. Vol. IXV. N 233. 2005: 147-172.

SANTAMARÍA, Daniel. Azúcar y sociedad en el noroeste argentino. Buenos Aires: IDES, 1986.

SAPELLI, Giulio. La empresa como sujeto histórico. En Barbero, M. Historia de empresas. Aproximaciones historiográficas y problemas en debate. Buenos Aires, CEAL, 1993: 103-115.

. La construcción social e histórica de la empresa: para un nuevo marco teórico. En Comin, F. y Aceña, P. M. La empresa en la historia de España. Madrid: Civitas, 1996.

SIBURU, Juan: Comentario del Código de Comercio Argentino precedido de una generalización del Derecho Comercial. Tomo V. Buenos Aires: Librería Jurídica de Valerio Abeledo, 1923.

SCHLEH, Emilio. El cincuentenario del centro azucarero argentino. Desarrollo de una industria en medio siglo. Buenos Aires: Centro Azucarero Argentino, 1944.

SCHVARZER, Jorge. La industria que supimos conseguir. Buenos Aires: Planeta, 1996.

SIERRA e IGLESIAS. Un tiempo que se fue. Vida y obra de los Hermanos Leach en el Departamento San Pedro, provincia de Jujuy (Argentina). Colección Arte y Ciencia, Serie 'Jujuy en el pasado', San Pedro de Jujuy, 1998. 
STEVENSON, H. y Sahlman, W.The Entrepreneurial process. en Burns, P. y Dewhusrt, J. (Eds). Small Business and Entrepreneurship. Basingstoke: Mc Millan Education, 1989.

SUZIGAN, Wilson. Indústria Brasileira. Origem e Desenvolvimento. Sao Paulo: Editora Hucitec-Editora da UNICAMP, 2000.

VALDALISO, J. y GARCÍA, López, S. Historia económica de la empresa. Nuevos Instrumentos Universitarios. Barcelona: Crítica, 2000.

VERÓN, Alberto. Sociedades Anónimas de Familia, Tomo I, (Empresa y constitución), Buenos Aires: Ed. Ábaco, 1979.

\section{Fuentes}

Archivo “Avellaneda \& Terán”, Libro Inventario y Balance (1892-1924); Libro de Actas Asambleas de Accionistas (1908-1949).

Anuario Estadístico de la Provincia de Tucumán. Dirección de Estadística de la Provincia. Edición Oficial. (varios años).

Banco Central de la República Argentina: C.I.D.E.A. Informe de la comisión. Buenos Aires, 1949.

Censo Nacional, 1895.Tomo III,Buenos Aires,TallerTipográfico de la Penitenciaría Nacional (1899).

Censo Nacional de la República Argentina, 1914, Talleres Gráficos Rosso y Cia., Buenos Aires (1919).

Revista Azucarera-La Industria Azucarera, órgano del Centro Azucarero Argentino (varios años). 